\title{
Development and validation of a one-dimensional snow-ice algae model against observations in Resolute Passage, Canadian Arctic Archipelago
}

\author{
L. Pogson, ${ }^{1}$ B. Tremblay, ${ }^{2}$ D. Lavoie, ${ }^{3}$ C. Michel, ${ }^{4}$ and M. Vancoppenolle ${ }^{5}$ \\ Received 28 January 2010; revised 30 December 2010; accepted 24 January 2011; published 15 April 2011.
}

[1] Ice algae are an important component of the carbon cycle in the Arctic. We investigate the dynamics of an ice algae bloom by coupling an ice algae-nutrient model with a multilayer $\sigma$ coordinate thermodynamic sea ice model. The model is tested with the simulation of an algal bloom at the base of first-year ice over the spring. Model output is compared with data from Barrow Strait in the Canadian Arctic Archipelago. Snow cover, through its influence on ice melt, is a dominant factor controlling the decline of the bloom in the model, a finding that supports past studies. The results show that under a higher snow cover $(20 \mathrm{~cm})$, biomass in the early stages of the algal bloom is less than expected from the observed data. This discrepancy is due to the severely light-limited algal growth, despite the close match between simulated and observed under-ice photosynthetically active radiation. This result raises issues of how photosynthetic parameters as well as radiative transfer is represented in one-dimensional ice models. This study also shows that for higher algal concentrations, when biomass is split over multiple layers rather than concentrated in one layer at the ice base, there is a reduction in algae accumulation, a result of self shading. In addition, experiments show a sensitivity of total biomass to the oceanic heat flux and ice layer thickness, both of which affect biomass loss at the ice base. Being able to accurately model physical conditions is essential before the seasonal dynamics of ice algae can be accurately modeled, and some recommendations for improvement are discussed.

Citation: Pogson, L., B. Tremblay, D. Lavoie, C. Michel, and M. Vancoppenolle (2011), Development and validation of a onedimensional snow-ice algae model against observations in Resolute Passage, Canadian Arctic Archipelago, J. Geophys. Res., 116, C04010, doi:10.1029/2010JC006119.

\section{Introduction}

[2] The Arctic is a region of particular interest to climate scientists, with general circulation models all suggesting that the Arctic Ocean and its surrounding seas are undergoing a more intense increase in temperature than anywhere else [Johannessen et al., 2004]. An important question to answer in the context of climate change is: how will warming affect the oceanic carbon cycle in the Arctic? Studies investigating the effects of these environmental changes on carbon biogeochemistry in the Arctic have shown an increase in phytoplankton production [e.g., Pabi et al., 2008; Lavoie et al., 2010]. With the reduction of sea ice, sea ice com-

\footnotetext{
${ }^{1}$ Canadian Ice Service, Environment Canada, Ottawa, Ontario, Canada. ${ }^{2}$ Department of Atmospheric and Oceanic Sciences, McGill University, Montreal, Quebec, Canada.

${ }^{3}$ Maurice Lamontagne Institute, Fisheries and Oceans Canada, Mont-Joli, Quebec, Canada.

${ }^{4}$ Arctic Research Division, Freshwater Institute, Fisheries and Oceans Canada, Winnipeg, Manitoba, Canada.

${ }^{5}$ Institut d'Astronomie et de Géophysique Georges Lemaître, Université Catholique de Louvain, Louvain-la-Neuve, Belgium.

Copyright 2011 by the American Geophysical Union. 0148-0227/11/2010JC006119
}

munities are expected to be less productive than in the past. This paper focuses on ice algae, which export carbon to the bottom of Arctic shelves [see, e.g., Juul-Pedersen et al., 2008]. Besides their role in the carbon cycle, ice algae can also contribute significantly to Arctic primary production and provide food to the pelagic and benthic food webs [Michel et al., 1996; Renaud et al., 2007; Tamelander et al., 2008].

[3] How algal blooms develop in the Arctic is in large part determined by the unique environmental conditions in the region. Before trying to model or predict how ice algae will be influenced by different conditions, it is important to first pinpoint what factors determine the rates of algal production and accumulation [Lavoie et al., 2005]. Ice algal variability under different conditions can largely be explained by changes in light, nutrients and substrate [Mundy et al., 2007]. Light is considered to be the factor controlling the onset of ice algal production in spring. Therefore, snow cover thickness and patchiness influence the temporal and spatial variability in ice algal distribution [e.g., Mundy et al., 2007]. Yet, nutrient replenishment to the sea ice matrix is essential to sustain production, and recent results from the Chukchi and Beaufort Seas [Gradinger, 2009; Mundy et al., 


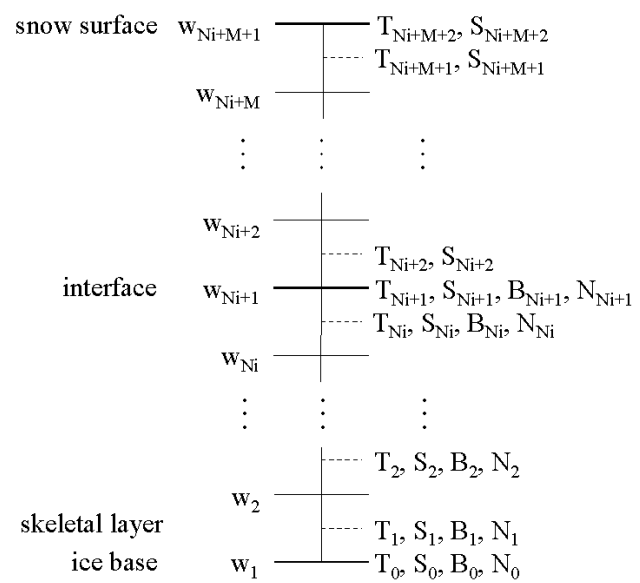

Figure 1. Numerical grid schematic. $N$ and $M$ are the number of ice and snow layers, respectively. The vertical velocity component $w$ is defined at the nodes of the grid and the temperature $T$, salinity $S$, biomass $B$, and nutrients $N$ are defined at the center of the grid ( $\mathrm{C}$ grid). Three additional temperatures, salinities, biomasses, and nutrients are defined at the surface, the base, and the snow-ice interface.

2009; Rozanska et al., 2009] support the hypothesis that nutrient supply from the water column determines the upper limit of ice algal production [Michel et al., 2006].

[4] Almost all salts and nutrients are dissolved within brine inclusions, which are dynamic and change size depending on the sea ice temperature and bulk salinity [see, e.g., Light et al., 2003]. For brine volume fractions above 5\%, the brine pockets coalesce and form brine channels [Eide and Martin, 1975; Golden et al., 1998]. Near the ice base, brine channels provide open pathways for brine drainage and material exchange between the ice and ocean. Brine dynamics supply nutrients in nonlinear interactions with biological sources and sinks [Vancoppenolle et al., 2010]. With most ice algae living locked in the brine channels, meltwater and brine flushed out during spring melt may carry algae with it, thereby accelerating the bloom decline [Meiners et al., 2003]. It is therefore important to consider brine dynamics and correctly representing melt rates when modeling ice algae.

[5] Ice algae in the Arctic are overwhelmingly located in the bottom 1 to $4 \mathrm{~cm}$ of growing first-year ice. This layer consists of thin platelets of ice called the skeletal layer [Maykut, 1985]. The bottom ice algal community has been the focus of past modeling studies in the Arctic, although ice algae have also been observed at all levels (surface, interior, and bottom) of Arctic sea ice [e.g., Cota and Smith, 1991]. Indeed, high biomass accumulations at the surface and in the interior of multiyear sea ice has been observed in the Central Arctic [Gradinger, 1999]. A large contrast between that study and those from coastal locations indicates that there are different biological regimes in Arctic sea ice depending on the region [Gradinger et al., 2009; Gradinger and Zhang, 1997], and suggests that to successfully model ice algae, more than just the community at the ice base needs to be considered.

[6] Not many sea ice modeling studies have dealt with modeling ice algae. In the first sea ice model dealing with ice algae [Arrigo et al., 1993], algal growth was formulated as a function of temperature, irradiance, salinity and nutrients. The Arrigo et al. [1993] model was designed for and applied to McMurdo Sound communities (Antarctica). In a later study, Lavoie et al. [2005] modeled a spring algal bloom in first-year Arctic ice, using a one snow layer/two ice layer model. These authors consider algae to be growing in the bottom $2 \mathrm{~cm}$ exclusively, with algal growth depending on irradiance, nutrients, and ice growth rate, and the upper water column supplying a flux of nutrients. The next ice algae modeling study, Jin et al. [2006], focused on algal bloom patterns in a coupled ice ocean ecosystem model, and also restricts biology to the bottom $2 \mathrm{~cm}$. Most recently, Nishi and Tabeta [2007] studied the role of ice algae in the ecosystem in Lake Saroma, using a coupled model with pelagic and ice ecosystems components that again limits algal growth to the bottom $2 \mathrm{~cm}$ of ice. In the most recent modeling study of ice algae, Tedesco et al. [2010] makes use of a time-varying biologically active layer, which represents the fraction of sea ice that is connected to the ocean via brine channels, and which acts as a rich habitat for microorganisms. This modeling study was done using a two snow layer/one ice layer/two intermediate layer thermodynamic model.

[7] This paper presents a snow-ice algae model with a more complex and physically based snow-ice component than in past models of the Arctic. The algae-nutrient component is based on that of Lavoie et al. [2005], while the snow-ice component is that of Huwald et al. [2005]. This model considers an arbitrary number of layers within snow and ice, and can include algae in all ice layers. A coordinate transformation allows for automatic relayering associated with changes in ice and snow thickness. This enables the model to better handle growth of algae into the ice, as well as expulsion at the ice base. This model introduces an alternative solution to Tedesco et al. [2010], in not constraining ice algae to the bottom $2 \mathrm{~cm}$ only. In the future, this model will be coupled to a brine dynamics model [Vancoppenolle et al., 2010] and used to simulate ice algae through the ice column. This model, as a result, could be developed for use in the Southern Ocean as well, where algae are present in more communities higher in the ice. This initial study presented here focuses on the algal community in the skeletal layer of first-year ice. We present sensitivity studies highlighting the effect of algal migration into higher layers. Model results are compared with observations to help identify aspects of the model that require improvements before further studies are conducted.

[8] The outline of the paper is as follows: section 2 presents the coupled snow-ice algae model. A description of the data used to force and validate the model is given in section 3. Section 4 outlines the model initial conditions. A discussion and comparison of simulation results to data, including sensitivity experiments, is presented in section 5 . The main conclusions drawn from the simulation results are summarized in section 6 .

\section{Model Description}

[9] An adapted version of the bulk ice algae model of Lavoie et al. [2005] is coupled to the one-dimensional $\sigma$ 


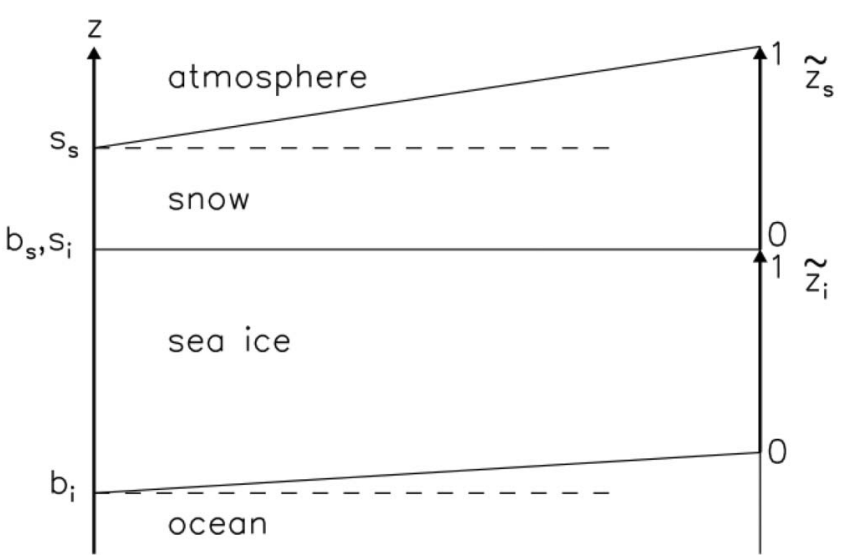

Figure 2. Coordinate transformation of the snow and ice components (adapted from Huwald et al. [2005]). The letters " $s$ " and " $b$ " denote the surface and base, subscripts " $s$ " and " $i$ " stand for snow and ice, and " $z$ " and " $\tilde{z}$ " are the original and transformed vertical coordinate, respectively.

coordinate multilayer thermodynamic model of Huwald et al. [2005]. A key feature of this model is that it employs a terrain-following coordinate system which includes a coordinate transformation in the governing heat conduction equation that naturally handles advection of ice. This allows for automatic redistribution of energy between layers in an energy-conserving manner, and also allows other tracers such as salt, nutrients and algae to be transferred between layers as the ice grows or melts (see Figure 1). Thus, while the focus of this paper is on ice algae at the ice base, it is possible for ice algae to be present in the ice interior as well. Here a brief description of the thermodynamic snow ice model is included for completeness. More details of the thermodynamic equations are given by Huwald et al. [2005].

\subsection{Thermodynamic Model}

\subsubsection{Snow and Ice Component}

[10] The evolution of the snow/ice thickness $(h)$ is calculated in terms of the snow/ice surface and base elevations (see Figure 2) as

$$
\begin{aligned}
& \frac{\partial s_{s}}{\partial t}=-\left(F_{n e t}+F_{c s}\right) /\left(\rho_{s} L_{f}\right) \text { if } F_{n e t}+F_{c s}>0, \\
& +p \cdot \rho_{w} / \rho_{s} \quad \text { if } T_{a} \leq 0^{\circ} C, \\
& \frac{\partial s_{i}}{\partial t}= \begin{cases}-\left(F_{n e t}+F_{c s}\right) /\left(\rho_{i} L_{f}\right) & \text { if } F_{n e t}+F_{c s}>0 \\
0 & \text { if } F_{n e t}+F_{c s}=0\end{cases}
\end{aligned}
$$

$$
\frac{\partial b_{i}}{\partial t}=\frac{F_{o c n}+F_{c b}}{\rho_{i} L_{f}}
$$

where $s$ and $b$ are the surface and base elevations, the subscripts 's' and ' $i$ ' denote snow and ice, $F_{n e t}$ is the net atmospheric heat flux (radiative and turbulent) at the surface, $F_{c s}$ and $F_{c b}$ are the conductive heat fluxes at the snow/ ice surface and ice base, $\rho_{i}, \rho_{s}$ and $\rho_{w}$ are the density of ice, snow and freshwater (see Table 1 for parameter and constant values), $p$ is a precipitation rate, $L_{f}(S, T)$ is the specific latent heat of fusion, $T_{a}$ is the air temperature, and $F_{\text {ocn }}$ is the ocean heat flux at the ice base.

[11] Following Huwald et al. [2005], we write the conservation of energy equation describing the temporal evolution of the snow and ice temperature as

$$
\rho \frac{\partial E}{\partial t}=\rho c_{p} \frac{\partial T}{\partial t}=-\frac{\partial F_{c}}{\partial z}+R
$$

where $E$ is the internal energy of the sea ice brine mixture, $c_{p}$

\begin{tabular}{|c|c|c|c|}
\hline Symbol & Definition & Value & Unit \\
\hline$a^{*}$ & mean chla-specific attenuation coefficient & 0.02 & $\mathrm{~m}^{2}(\mathrm{mg} \text { chla })^{-1}$ \\
\hline$\alpha^{B}$ & photosynthetic efficiency & see Table 2 & $\operatorname{mg~C}(\mathrm{mg} \text { chla })^{-1} \mathrm{~h}^{-1}\left(\mu \text { Einst } \mathrm{m}^{-2} \mathrm{~s}^{-1}\right)^{-1}$ \\
\hline$\beta$ & empirical constant & 0.1172 & $\mathrm{Wm}^{-1} \mathrm{psu}^{-1}$ \\
\hline$\gamma$ & empirical constant & $1.8 \times 10^{4}$ & $\mathrm{~J}^{\circ} \mathrm{C} \mathrm{kg}^{-1} \mathrm{psu}^{-1}$ \\
\hline$c_{p 0}$ & heat capacity of freshwater ice or snow & $2.06 \times 10^{3}$ & $\mathrm{~J} \mathrm{~kg}^{-1} \mathrm{~K}^{-1}$ \\
\hline$c_{p o}$ & heat capacity of ocean water at $30 \mathrm{psu}$ & $3.99 \times 10^{3}$ & $\mathrm{~J} \mathrm{~kg}^{-1} \mathrm{~K}^{-1}$ \\
\hline$D$ & diffusion coefficient of silicate & $1 \times 10^{-9}$ & $\mathrm{~m}^{2} \mathrm{~s}^{-1}$ \\
\hline$f r$ & fraction of absorbed heat energy released as heat by algae & 0.9 & dimensionless \\
\hline$i_{0}$ & fraction of net shortwave radiation penetrating the snow or ice surface & $0.5,0.15$ & \\
\hline$k_{i 0}$ & thermal conductivity of freshwater ice & 2.03 & $\mathrm{Wm}^{-1} \mathrm{~K}^{-1}$ \\
\hline$K_{s}$ & half-saturation constant for silicate uptake & 4.0 & $\mathrm{mmol} \mathrm{m} \mathrm{m}^{-3}$ \\
\hline$\kappa_{i}$ & bulk extinction coefficient of ice, nonmelt to melt & $1.2-0.8$ & $\mathrm{~m}^{-1}$ \\
\hline$\kappa_{s}$ & bulk extinction coefficient of snow, nonmelt to melt & $14-7.5$ & $\mathrm{~m}^{-1}$ \\
\hline$\nu$ & kinematic viscosity of seawater & $1.85 \times 10^{-6}$ & $\mathrm{~m}^{2} \mathrm{~s}^{-1}$ \\
\hline$P_{m}^{B}$ & maximum photosynthetic rate & see Table 2 & $\operatorname{mg~C~(mg~chla~})^{-1} \mathrm{~h}^{-1}$ \\
\hline$\rho_{i}$ & density of freshwater ice & 917 & $\mathrm{~kg} \mathrm{~m}^{-3}$ \\
\hline$\rho_{s}$ & density of snow & 330 & $\mathrm{~kg} \mathrm{~m}^{-3}$ \\
\hline$\rho_{w}$ & density of freshwater & 1000 & $\mathrm{~kg} \mathrm{~m}^{-3}$ \\
\hline$\phi$ & flushing loss term & 0.03 & $\mathrm{~m}^{-1}$ \\
\hline$w_{\text {crit }}$ & critical ice growth rate & 1.7 & $\mathrm{~cm} \mathrm{~d}^{-1}$ \\
\hline
\end{tabular}
is the heat capacity, $F_{c}=-k(\partial T / \partial z)$ is the conductive heat flux in the snow or ice, and $R$ is the absorbed shortwave energy per unit volume.

Table 1. Physical Parameters and Constants Used in the Model 
[12] The temperature and salinity-dependent sea ice heat capacity $\left(c_{p}\right)$ and bulk thermal conductivity $\left(k_{i}\right)$ are written following Untersteiner [1961]

$$
c_{p}(S, T)=c_{p 0}+\frac{\gamma S}{T^{2}} \quad \text { and } \quad k_{i}(S, T)=k_{i 0}+\frac{\beta S}{T},
$$

where $c_{p 0}$ and $k_{i 0}$ are the specific heat capacity and thermal conductivity of ice with zero salinity, and $\beta$ and $\gamma$ are empirical constants.

[13] Using Beer's law, $R$ is defined as

$$
R=\left\{\begin{array}{cc}
F_{p s} \kappa_{s} e^{-\kappa_{s}\left(s_{s}-z\right)} & \text { for } b_{s}<z<s_{s}, \\
F_{p i} \kappa_{i} e^{-\kappa_{i}\left(s_{i}-z\right)} & \text { for } b_{i}<z<s_{i},
\end{array}\right.
$$

with

$$
\begin{array}{ll}
F_{p s}=F_{s w}(1-\alpha) i_{0} & \text { at the snow or ice surface, } \\
F_{p i}=F_{p s} e^{-\kappa_{s} h_{s}} & \text { at the snow - ice interface, }
\end{array}
$$

where $F_{p s}$ and $F_{p i}$ are the shortwave radiation at the snow surface and snow-ice interface respectively, $\kappa_{s}$ and $\kappa_{i}$ are the extinction coefficients for snow and ice, $F_{s w}$ is the surface shortwave radiation, $\alpha$ is the snow or ice albedo, and $i_{0}$ is the surface transmission coefficient (different for snow and ice). At the surface, the incident shortwave radiation $F_{s w}$ is split into three parts: a reflected part $\alpha F_{s w}$, a fraction absorbed directly at the surface $(1-\alpha)\left(1-i_{0}\right) F_{s w}$, and a part penetrating into the snow or ice $(1-\alpha) i_{0} F_{s w}$.

[14] The choices for the parameters in the radiative model are especially important for this study, since the amount of radiation reaching the ice algae at the ice base must be accurately modeled. Therefore, although $\alpha$ is set as constant for snow or ice by Huwald et al. [2005], in this model it is parameterized using surface temperatures and ice thickness in an attempt to capture the changes in albedo over the melt season [Flato and Brown, 1996].

[15] The attenuation coefficients used in the model for dry snow $\kappa_{s}$ and cold ice $\kappa_{i}$ are 14 and $1.2 \mathrm{~m}^{-1}$, respectively [Grenfell and Maykut, 1977; Smith et al., 1988]. For melting snow and ice, $\kappa_{s}$ and $\kappa_{i}$ have values of 7.5 [Grenfell and Maykut, 1977] and $0.8 \mathrm{~m}^{-1}$ [Light et al., 2008], respectively. In the model, $\kappa_{s}$ and $\kappa_{i}$ are initially set to the higher, cold season values. As a rough formulation, when melting is initiated (calculated in the model as when surface temperature is at melting point and the net heat flux at the surface is directed into the ice), $\kappa_{s}$ and $\kappa_{i}$ linearly decrease until reaching their melt values over the period of 2 weeks.

[16] Following Grenfell and Maykut [1977], we use an average value of 0.5 for $i_{0}$ of first-year ice. Much less light penetrates through snow, and in past model studies, values of $i_{0}$ for snow range from 0 to 0.08 [Huwald et al., 2005; Ohmura, 1984], resulting in more radiation contributing to the surface energy budget. As melt occurs, more light penetrates through ice and snow surface layers [Grenfell and Maykut, 1977], suggesting that while values below 0.1 may be appropriate for drier snow, a higher value may be needed for the melt season. In this study, we adopt a value of $i_{0}$ for snow equal to 0.15 [Vancoppenolle et al., 2010]. With this higher value, less radiation will contribute to melting at the surface while more radiation will penetrate deeper into the ice. Despite the lack of data to support this value, 0.15 under snow leads to correct photosynthetically active radiation (PAR) under sea ice in spring.

\subsubsection{Algae Thermodynamic Effects}

[17] Since the absorption of shortwave radiation in sea ice is 3-13 times larger for wavelengths longer than $700 \mathrm{~nm}$ [Grenfell and Maykut, 1977], it is assumed that only the visible range $(400-700 \mathrm{~nm})$ penetrates the ice interior [Zeebe et al., 1996]. Thus in equation (7), shortwave radiation $R$ and PAR (400-700 $\mathrm{nm}$ ) are used interchangeably. Of the light absorbed by ice algae, only a fraction is used in photosynthesis, while the rest of the energy is released as heat. We use a photosynthetic efficiency of $10 \%$, which is a median value from estimates for ice algae by Zeebe et al. [1996] and as per Lavoie et al. [2005]. Taking into account the absorption of energy by the ice algae, $R$ (equation (7)) is rewritten as

$$
R= \begin{cases}F_{p s} \kappa_{s} e^{-\kappa_{s}\left(s_{s}-z\right)} & \text { for } b_{s}<z<s_{s}, \\ F_{p i}\left(\kappa_{i}+f r \cdot \kappa_{a}\right) e^{-\left(\kappa_{i}+\kappa_{a}\right)\left(s_{i}-z\right)} & \text { for } b_{i}<z<s_{i},\end{cases}
$$

where $F_{p s}$ remains unchanged since algae are generally not present in the snow, $f r$ is the percentage of energy absorbed by the algae that is released as heat, and $\kappa_{a}$ is the attenuation coefficient for algae, which varies linearly with the concentration of algae [Kirk, 1983]

$$
\kappa_{a}=a^{*} B,
$$

where $a^{*}$ is the mean chla-specific attenuation coefficient $\left(0.02 \mathrm{~m}^{2} \mathrm{mg} \mathrm{chla}^{-1}\right.$ [Lavoie et al., 2005]) and $B$ (in $\mathrm{mg}$ chla $\mathrm{m}^{-3}$ ) is the algal biomass. Equation (8) implies that if algae grows higher into the ice, the available shortwave radiation deeper in the ice is reduced, and by how much is dependent on algal concentration.

\subsection{Ice Algae-Nutrient Model}

[18] The ice algae-nutrient component of this model has been adapted from Lavoie et al. [2005] to be included in all ice layers. The evolution equations for the biomass and the nutrient concentration of silicic acid $N\left(\mathrm{mmol} \mathrm{m}^{-3}\right)$ in each of the ice layers can be written as

$$
\begin{gathered}
\frac{\partial B}{\partial t}=B[\mu-G], \\
\frac{\partial N}{\partial t}=-N_{u p},
\end{gathered}
$$

where $\mu$ is the ice algal growth rate, $G$ is the grazing rate, and $N_{u p}$ is the uptake rate of nutrient by the algae calculated as by Lavoie et al. [2005]. $G$ is zero in the interior ice layers, and in the skeletal layer $G=0.1 \mu$ [Lavoie et al., 2005]. The movement of tracers between layers enabled by this model removes the need to introduce loss terms for biomass and nutrients due to ice melt/growth.

[19] Bottom ice algae are largely dominated by diatoms which require silicon, nitrogen and phosphate for their growth. Silicic acid has been considered the most limiting nutrient in our study area of Resolute Passage, since all three nutrients are abundant in the mixed layer, but unlike $\mathrm{N}$ and $\mathrm{P}$, the dissolution of biogenic silica occurs too slowly for ice algae. While this is the nutrient included in this model, there 
is recent evidence that finds nitrate to be a limiting nutrient for ice algae in other regions [Rozanska et al., 2009; Mundy et al., 2009] and should perhaps be considered in future model studies. The nutrient uptake rate by ice algae is given by

$$
N_{u p}=\mu B \frac{N}{C h l a},
$$

where $N / C h l a=17$ is the average ratio of biogenic silica to chla measured over the study period (mg Si: mg chla) Lavoie et al. [2005].

[20] The ice algal growth rate $\mu$ is calculated as

$$
\mu=\mu_{\max } \min \left(N_{\text {lim }}, L_{\text {lim }}\right),
$$

where $\mu_{\max }$ is a maximum temperature-dependent ice algal growth rate $\left(\log _{e}\right)$ predicted by Eppley [1972], and $N_{\text {lim }}$ and $L_{\text {lim }}$ are the nutrient and light limiting factors, respectively. Following Lavoie et al. [2005], $N_{\text {lim }}$ is written as

$$
N_{\text {lim }}=\frac{N}{K_{s}+N}
$$

where $K_{s}$ is the half-saturation constant for $\mathrm{Si}(\mathrm{OH})_{4}$ uptake ( $4 \mathrm{mmol} \mathrm{m}^{-3}$ [Sarthou et al., 2005]), and $L_{\text {lim }}$ is written as

$$
L_{\text {lim }}=\tanh \left(\frac{\alpha^{B} R_{z_{0}}}{P_{m}^{B}}\right)
$$

where $\alpha^{B}$ is the photosynthetic efficiency, $P_{m}^{B}$ is the maximum (light-saturated) photosynthetic rate of ice algae in the same area [Cota and Horne, 1989; Smith et al., 1988] and $R_{z 0}$ is the PAR reaching the top of the algal layer, obtained using Beer's law. In equation (15), $R_{z 0}$ is converted from $\mathrm{W} \mathrm{m} \mathrm{m}^{-2}$ to Einst $\mathrm{m}^{-2} \mathrm{~s}^{-1}$ with a ratio of $4.56 \times 10^{-6}$ following Lavoie et al. [2005] and Morel and Smith [1974].

[21] The principal source of nutrients for algae in the skeletal layer is the ocean mixed layer, through convection and turbulence in the water column, which combine with brine convection in winter. While these other sources can become important for algal communities higher in the ice, they are not included in the present model. The nutrient flux $\left(F_{N}\right)$ to the skeletal layer depends on the nutrient concentration in the mixed layer and the thickness of the viscous sublayer. Following Lavoie et al. [2005], it is written as

$$
F_{N}=\frac{N_{m i x}-N}{h_{\nu}} D,
$$

where $N_{\text {mix }}-N$ is the nutrient concentration gradient across the viscous sublayer of thickness $h_{\nu}$, and $D\left(1 \times 10^{-9} \mathrm{~m}^{2} \mathrm{~s}^{-1}\right.$ [Lavoie et al., 2005]) is the diffusion coefficient of silicic acid. The nutrient equation in the skeletal layer is then given by

$$
\frac{\partial N}{\partial t}=\frac{F_{N}}{d z_{i}}-N_{u p}
$$

where $d z_{i}$ is the thickness of the skeletal layer. The nutrient concentration of new ice is calculated as

$$
N=\nu_{b} N_{w},
$$

where $\nu_{b}$ is a fractionation coefficient, set equal to 1 , and $N_{w}$ is the nutrient concentration in seawater [Vancoppenolle et al., 2010].

[22] In equation (16), the viscous sublayer thickness is calculated after Tennekes and Lumley [1972]

$$
h_{\nu}=\frac{\nu}{u_{\tau}}
$$

where $\nu$ is the kinematic viscosity of seawater $(1.85 \times$ $10^{-6} \mathrm{~m}^{2} \mathrm{~s}^{-1}$ ) and $u_{\tau}$ is the friction velocity.

\subsection{Coordinate Transformation}

[23] Following Huwald et al. [2005], a transformation to terrain-following coordinates is applied for both the snow and ice, with the base and surface positioned at $\tilde{z}=0$ and $\tilde{z}=1$ (Figure 2)

$$
\tilde{z}=\frac{z-b}{s-b} \quad \text { and } \quad \tilde{t}=t
$$

where $s$ and $b$ are equal to $s_{s}$ and $b_{s}$ for the snow layer, and $s_{i}$ and $b_{i}$ for the ice layer. Transformed variables are labelled with tilde. The transformed energy equations for snow and ice are

$$
\begin{aligned}
& \rho\left(\frac{\partial\left(h_{s} \tilde{E}_{s}\right)}{\partial \tilde{t}^{\prime}}+\frac{\partial\left(\tilde{w}_{s} h_{s} \tilde{E}_{s}\right)}{\partial \tilde{z}_{s}}\right)=\frac{1}{h_{s}^{2}} \frac{\partial}{\partial \tilde{z}_{s}}\left(k_{s} \frac{\partial \theta_{s}}{\partial \tilde{z}_{s}}\right)+h_{s} \tilde{R} \\
& \quad \text { for } 0<\tilde{z}_{s}<1, \\
& \rho\left(\frac{\partial\left(h_{i} \tilde{E}_{i}\right)}{\partial \tilde{t}}+\frac{\partial\left(\tilde{w}_{i} h_{i} \tilde{E}_{i}\right)}{\partial \tilde{z}_{i}}\right)=\frac{1}{h_{i}^{2}} \frac{\partial}{\partial \tilde{z}_{i}}\left(k_{i} \frac{\partial \theta_{i}}{\partial \tilde{z}_{i}}\right)+h_{i} \tilde{R}
\end{aligned}
$$$$
\text { for } 0<\tilde{z}_{i}<1 \text {, }
$$

where subscripts denote 's' and 'i' denote snow and ice, $h=$ $s-b$, and $\tilde{w}=\partial \tilde{z} / \partial \tilde{t}$. The radiative source term is also transformed, and is obtained by substituting equation (20) into equation (8)

$$
\tilde{R}= \begin{cases}F_{p s} \kappa_{s} e^{-\kappa_{s}\left(1-\tilde{z}_{s}\right) h_{s}} & 0<\tilde{z}_{s}<1 \\ F_{p i}\left(\kappa_{i}+f r \cdot \kappa_{a}\right) e^{-\left(\kappa_{i}+\kappa_{a}\right)\left(1-\tilde{z}_{i}\right) h_{i}} & 0<\tilde{z}_{i}<1\end{cases}
$$

[24] Equations (10) and (17) can be rewritten in terms of the transformed coordinate $\tilde{z}$ as

$$
\begin{gathered}
\frac{\partial\left(h_{i} \tilde{B}\right)}{\partial \tilde{t}}+\frac{\partial\left(\tilde{w}_{a} h_{i} \tilde{B}\right)}{\partial \tilde{z}_{i}}=h_{i} \tilde{B}[\tilde{\mu}-\tilde{G}], \\
\frac{\partial\left(h_{i} \tilde{N}\right)}{\partial \tilde{t}}+\frac{\partial\left(\tilde{w} h_{i} \tilde{N}\right)}{\partial \tilde{z}_{i}}=\frac{\tilde{F}_{N}}{\tilde{d} z_{i}}-h_{i} \tilde{N}_{u p},
\end{gathered}
$$

where $0<\tilde{z}_{i}<1$. The transformation introduces an additional advection term which naturally handles the transport of ice algae and nutrients from one model layer to the next, when the ice thickness is changing. $w_{a}$ is a separate advection velocity used in the calculation of algae, which takes into account the ability of the algae to maintain their vertical position somewhat during ice growth. Below a critical ice growth rate value $w_{c r i t}$, ice algae at the ice base 
Table 2. Photosynthetic Parameters for the Three Data Sites ${ }^{\text {a }}$

\begin{tabular}{lccc}
\hline Site & $\alpha^{B}$ & $P_{m}^{B}$ & $\alpha^{B} / P_{m}^{B}$ \\
\hline PAR & 0.055 & 0.285 & 0.193 \\
LSC & 0.03 & 0.3 & 0.1 \\
HSC & 0.12 & 0.27 & 0.444 \\
\hline
\end{tabular}

${ }^{\mathrm{a}}$ Described in section 2.2. See Table 1 for units.

are able to maintain their position, and not be transported upward as the ice grows [Welch and Bergmann, 1989]. If the ice growth rate is larger than $w_{\text {crit }}$, the algae are trapped within the ice matrix and will be transported upward as the ice grows at the base. $w_{a}$ can then be written as follows:

$$
\begin{array}{ll}
w_{a}=\max \left(w-\left|w_{\text {crit }}\right|, 0\right) & \text { for ice growth, } \\
w_{a}=w & \text { for ice melt. }
\end{array}
$$

A value of $1.7 \mathrm{~cm} \mathrm{~d}^{-1}$ is used for $w_{\text {crit }}$ following Lavoie et al. [2005].

\subsection{Numerical Scheme}

[25] The terms in the transformed algae and nutrient equations are treated similarly to the terms in the energy equation of Huwald et al. [2005]. The time derivative is discretized using a forward step and the advection term is evaluated implicitly using an energy-conserving first-order upstream scheme.

\section{Data and Forcing}

[26] Data were collected from May to July 2002 at a landfast ice station in Resolute Passage $\left(74^{\circ} 42.5^{\prime} \mathrm{N}\right)$ in the Canadian Arctic Archipelago. In this area, the polar night lasts from the second week of November to the first week of February. Surface waters flowing through the area are nutrient rich and of Pacific origin [Jones et al., 2003]. Meteorological data including wind, air temperature and relative humidity, were taken at the sampling station, and cloud cover fraction data were obtained from an Environment Canada station located about $30 \mathrm{~km}$ southeast of the sampling site. Under-ice temperature and conductivity measurements were taken every 5 minutes by a Sea-Bird SBE37 probe moored at $1 \mathrm{~m}$ below the ice. Salinity in the water column was measured with a CTD SBE 19 Seacat profiler. Nutrient data were taken from water column samples collected using Niskin bottles at four depths $(2.5,5,10$ and $25 \mathrm{~m}$ ) at 3 to 4 day intervals. Nutrient subsamples were taken from the Niskin bottles, and frozen in liquid nitrogen until concentrations of $\mathrm{Si}(\mathrm{OH})_{4}$ were determined with a Technicon autoanalyzer.

[27] Measurements of under-ice PAR were taken every 15 minutes using a $2 \pi$ LiCOR quantum sensor (Li-192SB) mounted on an under ice arm horizontally at $0.5 \mathrm{~m}$ underneath the ice, and connected to a LiCOR 1400 data logger. Daily snow thickness was also obtained at this "PAR" site. Ice algae were sampled at two sites with different snow thicknesses (roughly $20 \mathrm{~cm}$ and $10 \mathrm{~cm}$ ), denoted the high snow cover (HSC) and low snow cover (LSC) sites. Algae samples were taken every 3 to 4 days from the bottom 2$4 \mathrm{~cm}$ of an ice core made using a MARK II coring system. The bottom $2-4 \mathrm{~cm}$ of each core, where most of the algal biomass was observed, was immediately cut off and put in a dark isothermal container. The cores were melted in surface seawater collected at the time of sampling and filtered through $0.22 \mu \mathrm{m}$ membrane filters. Ice and snow thickness data were recorded at the same location. Coring positions for the LSC and HSC sites were chosen where snow thickness was close to 10 and $20 \mathrm{~cm}$, respectively. This results in some spatial variability for the algae samples as well as ice and snow thickness measurements. For this reason, simulated snow thickness time series evolution is not compared directly with observations, rather the snow observations are used as an upper bound since the model takes into account melt. This is an area of undeformed, uniform first-year ice, so the spatial variability of ice thickness is not significant. While snow and ice thickness data are available over the entire study period at the LSC site, data at the HSC site do not extend past day 168, when high snow cover areas no longer exist. A complete description of the data set are given by Lavoie et al. [2005].

[28] Meteorological data (air temperature, cloud cover data) were used to calculate the heat flux at the ice/snow surface, with $F_{s w}$ parameterized following Parkinson and Washington [1979]. Wind and relative humidity data were used to calculate the sensible and latent heat fluxes. The oceanic heat flux is calculated using under-ice temperature and salinity following McPhee [1992]

$$
F_{o c n}=\rho_{o} c_{p o} C_{o i} u_{\tau}\left(T-T_{f}\right),
$$

where $\rho_{o}, c_{p o}$, and $T$ are the mixed layer density, heat capacity and temperature, $C_{o i}$ is the ocean-ice sensible heat transfer coefficient, and $T_{f}$ is the salinity-dependent freezing point temperature. A value of $c_{p o}=3990$ is used, $T$ is taken from data, $\rho_{o}$ is calculated from $T$ and $S$ data, $C_{o i}$ is calculated after Mellor and Kantha [1989], and $u_{\tau}$ is fitted to tidal cycle data as with Lavoie et al. [2005].

[29] The nutrient flux into the skeletal layer (equation (16)) was calculated using the nutrient concentration data collected at water depth of $2.5 \mathrm{~m}\left(N_{m i x}\right)$. Viscous sublayer thickness $h_{\nu}$ (equation (19)) is calculated using the fitted values $u_{\tau}$ from Lavoie et al. [2005]. The photosynthetic parameters $\alpha^{B}$ and $P_{m}^{B}$ (for light limitation, defined in section 2.2) vary from site to site, due to different shade adaptations. The values for the three observation sites follow Lavoie et al. [2005] (see Table 2).

[30] Over the study period, air temperature at the sampling site was between $-18^{\circ} \mathrm{C}$ at night in May and $5^{\circ} \mathrm{C}$ during the daytime in June. Calculated values of shortwave radiation varied from 5 to $650 \mathrm{~W} \mathrm{~m}^{-2}$. In the water column, the under-ice temperature ranged between -1.78 and $-1.50^{\circ} \mathrm{C}$, and salinity was between 32.12 and 32.73 psu. The silicic acid concentration at $2.5 \mathrm{~m}$ below the ice varied from 15 to $23 \mathrm{mmol} \mathrm{m}^{-3}$.

\section{Model Setup}

[31] The model was run during the 2002 spring bloom from days 130 (May 10) to 182 (July 1), when data were collected from each of the three data sites (PAR, HSC, LSC). The number of snow layers used by the model is 5, and the number of ice layers is 90 . The corresponding mean ice layer thickness is $1.5 \mathrm{~cm}$. Although this model accommodates algae in all ice layers, only the bottom two ice 

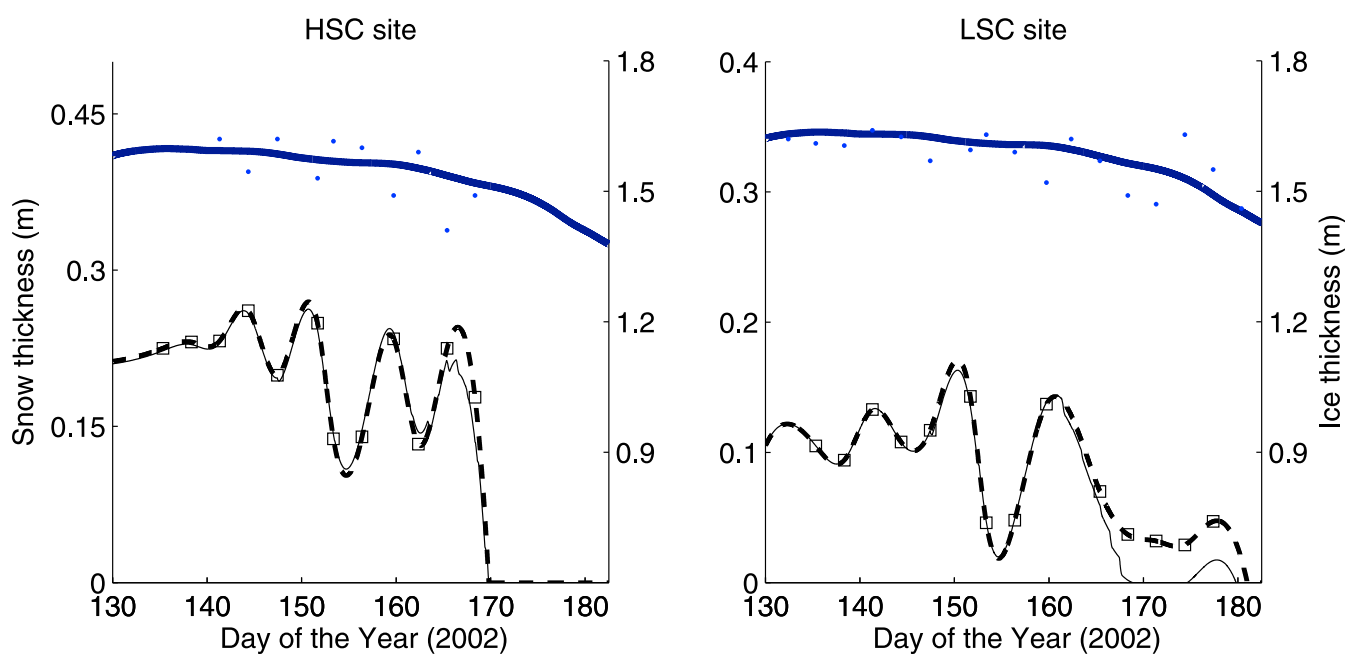

Figure 3. Observed (dots) and simulated ice thickness (blue line) and observed (squares) and interpolated snow thickness (solid black line) compared to simulated snow thickness (dashed black line) at (left) HSC and (right) LSC sites.

layers are initially set to be nonzero. This distribution is to match observations, which show algae concentrated in the bottom $3 \mathrm{~cm}$, and that $96 \%$ of the algal biomass (chla) was located in the bottom $1.5 \mathrm{~cm}$. Based on measurements, our

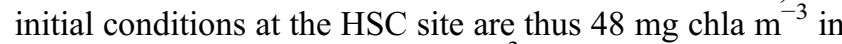
the bottom layer and $2 \mathrm{mg} \mathrm{chla} \mathrm{\textrm {m } ^ { - 3 }}$ in the next layer, for a total of $50 \mathrm{mg}$ chla $\mathrm{m}^{-3}$ in both layers. At the LSC site, biomass in the bottom layer is set to $1152 \mathrm{mg} \mathrm{chla}^{-3}$ and in the next layer $48 \mathrm{mg}$ chla $\mathrm{m}^{-3}\left(1200 \mathrm{mg}\right.$ chla $\mathrm{m}^{-3}$ in both layers). Snow thicknesses were set to 21 and $10.5 \mathrm{~cm}$ at the HSC and LSC sites, respectively, as observed in the field. Ice thicknesses were 1.58 and $1.62 \mathrm{~m}$ at the HSC and LSC sites, respectively.

\section{Results}

\subsection{Ice/Snow Thickness Comparison}

[32] Correctly simulating the ice and snow thicknesses is important, because of the effect on PAR reaching the ice algae and on algal loss through basal melt. Following Huwald et al. [2005], snow thickness in the model is prescribed before the start of melt (due to the absence of reliable snow precipitation data) and the snow thickness evolution is calculated during the melt period. During the melt phase (after day 167), simulated snow thickness values diverge somewhat from observations (see Figure 3). This difference is because the model considers a fixed point in space while sampling points varied. Simulated ice thickness is also compared to measured ice thickness over the model run period. Overall the simulated ice thickness fits the data set well (see Figure 3).

\subsection{PAR at the Ice Base}

[33] Given the strong dependence of ice algae growth on light levels, it is important to evaluate the model's ability to simulate penetrating shortwave radiation through the snow and ice. In the following, we compare simulated shortwave radiation reaching the ice base to the under-ice PAR data measured. PAR transmission to the ice-water interface is dependent on the light attenuation and penetrating coeffi- cients used by the model. Measured under-ice PAR is used to validate the light attenuation $\left(\kappa_{s}, \kappa_{i}\right)$ and penetrating coefficients $\left(i_{0}\right)$ used in the subsequent model/data comparison discussed in section 5.3.

[34] Light reaching the ice-water interface depends on snow and ice thickness, as well as the concentration of the ice algae itself. To this end, we compare sea ice and snow thickness and biomass content to observations. At the PAR site, ice algal samples were not taken, so the model output of biomass was compared to samples taken at the LSC and HSC sites (Figure 4d). The biomass simulated at the PAR site varies between the data sets of the 2 sites, providing a reasonable range of values. The decrease in ice algal biomass later in the bloom leads to increased under-ice PAR. Snow thickness was measured at the PAR site, but ice thickness was not. Since the spatial variability of the ice is small, the simulated ice thickness temporal evolution is compared to ice thickness observations from the HSC and LSC sites. Simulated snow thickness is slightly underestimated during the melt phase (days 160-170) but not a significant amount (Figure 4c). After day 168 the snow is completely gone. The disappearance of the light-blocking snow cover explains the rapid increase in under-ice PAR seen in Figures $4 \mathrm{a}$ and $4 \mathrm{~b}$.

[35] Between day 130 and 155, simulated under-ice PAR compares well with observations, and significantly improves on results by Lavoie et al. [2005], likely because of a more realistic value for $i_{0}$. Differences between simulated and observed under-ice PAR are more significant after about day 155 (Figures 4a and 4b). From day 155 to 170 the snow cover completely melts. Although measured snow cover thickness at the PAR site does not change significantly from day 155 to 163 , the amount of measured under-ice PAR is seen to increase. This suggests that $\kappa_{S}$ should perhaps decrease to an even lower value, or that $i_{0}$ for snow should also allow increasingly more light penetration as snow melting progresses. To the authors' knowledge however, no detailed measurements of $i_{0}$ for different snow conditions exist in the literature. After day 168, the snow cover has disappeared, and the model underestimates under-ice PAR 

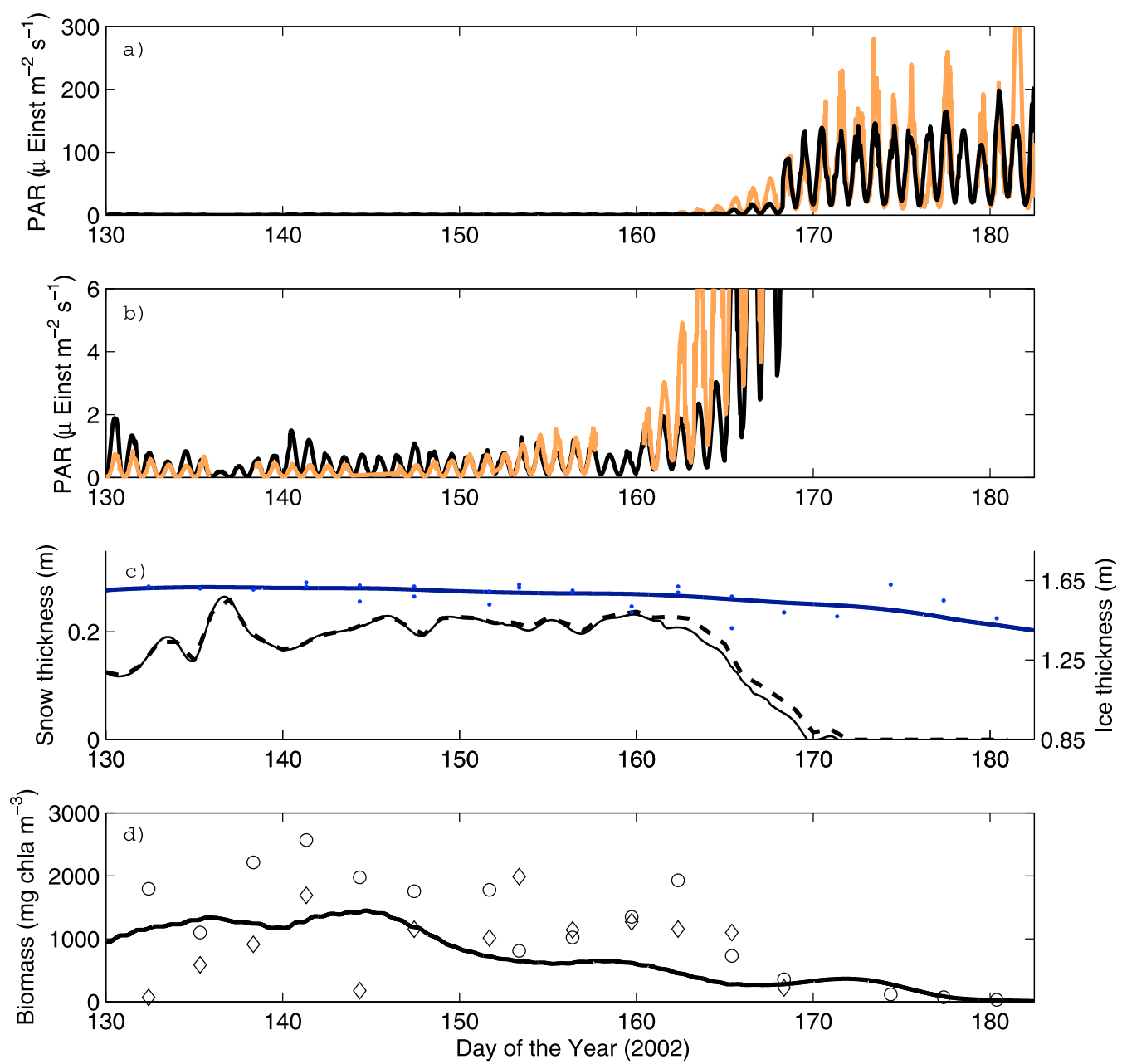

Figure 4. Time series of (a) observed under-ice PAR (orange line) compared with simulated under-ice PAR (black line), (b) magnification of simulated and observed under-ice PAR, (c) observed (black dashed line) and simulated (solid black line) snow thickness and simulated ice thickness (blue line) and ice thickness observed at the HSC and LSC sites (dots), and (d) simulated chla biomass (black line) compared with observed biomass at the LSC (circles) and HSC (diamonds) sites.

during the rest of the study period. Because transmission of radiation increases through ice as well as snow, it is possible that $\kappa_{i}$ and $i_{0}$ for ice should allow even more light as melt progresses.

\subsection{Algal Bloom}

[36] Over the study period, ice growth rate at the base is not large enough to cause ice algae to be transported upward within the sea ice. For this reason, the biomass results presented are summed over the bottom two layers only. Silicate concentration is referred to as the limiting nutrient, although other nutrients may also be important. At the start of the bloom, the two sites have similar light limitations despite a significantly thicker snow cover at the HSC site (Figures 5a and $5 \mathrm{~b}$ ). Even though more light initially reaches the base of the ice at the LSC site, differing adaptation by the algae to light conditions at the sites (described using photosynthetic parameters $\alpha^{B}$ and $P_{m}^{B}$, see Table 2) results in similarly low initial light limitations (equation (15)). At the LSC site, simulated ice algae display steady growth similar to observations (Figure 5d). With a much lower initial biomass, ice algae at the HSC site grows very little and does not match the rapid initial growth seen in the observations (Figure 5c). Because of this initial discrepancy, the simulated biomass at the HSC site is underestimated over the entire study period (see section 5.4.1 for discussion). With so little algae growing, the silicate concentration remain plentiful and no change in nutrient limitation occurs (Figure 5a). This slow initial growth by the ice algae at the HSC site may not have been seen by Lavoie et al. [2005] because in that study, PAR was overestimated in the presence of snow.

[37] In the middle stage of the bloom, the calculated light limitation curves at both sites (Figures $5 \mathrm{a}$ and $5 \mathrm{~b}$ ) have oscillatory patterns driven by the snow depth profile, with light availability peaking during periods of minimum snow depth. Around the middle of the bloom, the algae transitions into a nutrient limitation phase at the LSC site as more light penetrates the thinner ice cover. After day 151 the largest decrease in simulated snow depth occurs at both sites (Figure 3), allowing more light to reach the algae at the base of the ice (Figures $5 \mathrm{c}$ and $5 \mathrm{~d}$ ). This heightened light availability causes a spurt in algal growth at the LSC site, in turn 

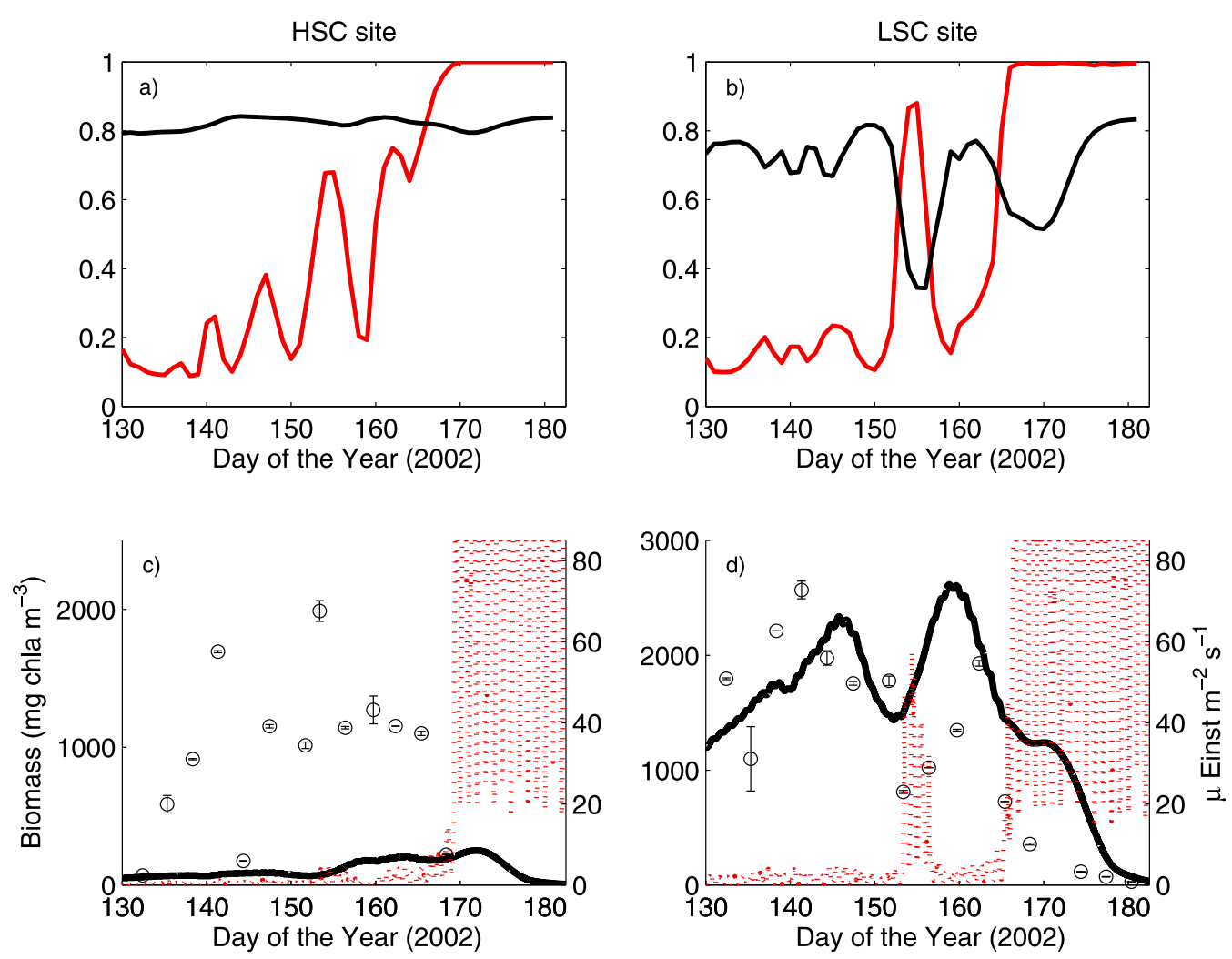

Figure 5. Model results versus observations for the (left) HSC and (right) LSC sites. (a and b) Nutrient (black line, $N_{\text {lim }}$ ) and light (red line, $L_{\text {lim }}$ ) limitation functions and (c and d) time series of observed (black circles) and simulated (black line) bottom ice biomasses and modeled PAR available at the top of the bottom ice layer (dotted red line). The vertical bars on ice algal biomass observations represent the standard deviation for duplicate samples.

increasing the uptake of nutrients and resulting in a sharp reduction of nutrients (Figure $5 b$ ). With a subsequent higher snow cover and light limitation, nutrients are replenished until about day 160, when snow cover is reduced again.

[38] A nutrient limitation remains through to the end of the bloom, but the nutrient supply recovers as the biomass declines at the end of the bloom season. When the snow depth reaches zero around day 171, there is ample light available at both sites. These results are in agreement with Lavoie et al. [2005] in their pattern of light and nutrient limitations.

[39] At the HSC site, algal growth and loss remain fairly similar over the study period (see Figure 6), with more growth occurring between day 150 and 160 when decreased
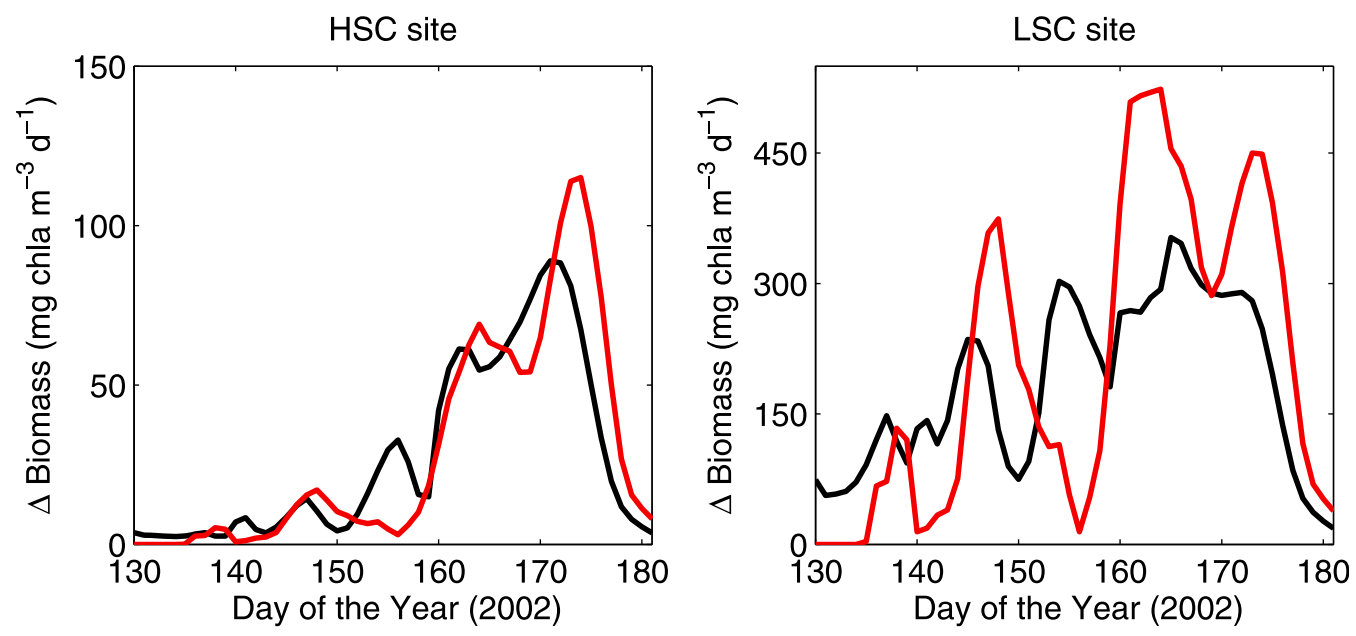

Figure 6. Simulated accumulation rate (black line) and loss rate through melt (red line) of bottom ice algal biomass for the (left) HSC and (right) LSC sites. 


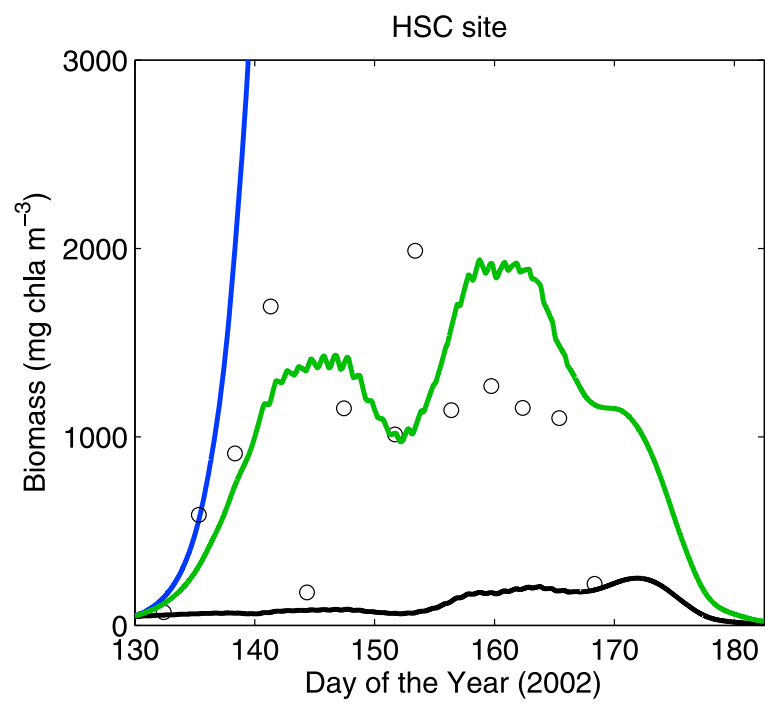

Figure 7. Simulated bottom biomass at the HSC site in the control run (black line), with no light limitation in the first 10 days (green line), and with no limitation on growth in the first 10 days (blue line).

snow cover allowed more light to reach the algae (see Figure 5a). The pattern of growth over the study period at the LSC site follows the pattern of the limitations shown in Figure $5 \mathrm{~b}$. Three large spikes of biomass loss occur about 14 days apart, and occur when the oceanic heat flux is highest and larger ice melt is simulated, leading to biomass loss at the ice base. The increased oceanic heat flux at these times is caused by a thinning of the viscous sublayer, due to the tidal cycle. These periods when loss is higher than growth correspond to the dips in biomass seen in Figure $5 \mathrm{~d}$. The decline of the bloom at the LSC site begins in early june (day 160), when loss overtakes the growth and is larger for the remainder of the study period. This timing is again consistent with the findings of Lavoie et al. [2005]. Therefore it seems that despite heightened light availability at the end of the study period, melting at the ice base and the associated biomass loss dominates and the bloom ends.

[40] It is important, when comparing simulated values of biomass with observations, to consider spatial variability. The model assumes the simulated algal bloom occurs in a fixed location in the ice, but the ice core locations varied at both sites, as the sampling method is disruptive. Since there was blowing snow over the study period, a core sample under a 10 or $20 \mathrm{~cm}$ snow cover might have previously been under a much different snow thickness during sampling 3 days earlier. Thus, biomass collected might not always reflect levels expected for the simulated snow cover. While this margin of error exists, results given in section 5.2 do suggest that the model underestimates the growth of ice algae under a heavy snow cover, and overestimates the biomass during the bloom decline. Factors surrounding these issues are discussed in section 5.4.

\subsection{Discussion}

\subsubsection{Growth Under Heavy Snow Cover}

[41] At the HSC site, the simulated increase in biomass from day 130 to 140 is much less than the increase seen in observations (see Figure 5c). Despite a substantial cover of snow, ice algae are still observed to grow quickly during this period. Since no algae was lost through melt at this time (see Figure 6), the slow increase of biomass must be because of the algae growth term. Figure 5a shows that the model underestimates growth during this period because of very limited light availability. Although observed and simulated under-ice PAR were compared at the PAR site and not the HSC site (see Figure 4b), the comparison shows that under a thicker, nonmelting snow cover, simulated PAR values are slightly overestimated. This indicates that if anything, algal growth in the model should be less limited by light than in reality.

[42] There are two main reasons for the light limitation problem. One possibility is that the amount of light reaching the algae in the model is correct, but the algae are low light adapted at the beginning of the season, and the photosynthetic parameters in the model do not account for this. Values for $\alpha^{B}$ and $P_{m}^{B}$ vary depending on light and nutrient conditions, but a well known relationship to calculate their values is not known. There is a wide range of acceptable values for each parameter, and the resulting possible combinations give a broad range of possible growth rates. This study illustrates that 1) selecting constant values for the photosynthetic parameters is an oversimplification that does not allow realistic modeling of ice algae over varying conditions and 2) the lack of knowledge of how to calculate these parameters based on light and nutrient conditions is a serious limitation of this type of modeling. This is an area that requires further work.

[43] The alternative reason is that algal light absorption is greater than what is parameterized in the model. One explanation for this is that while the model only parameterizes light received from directly above, any basal sea ice community would also receive diffuse light from other directions. This additional PAR could be parameterized in the model by using a prescribed snow depth distribution function in the computation of radiative transfer. Another explanation involves how in situ absorption in sea ice is parameterized. J. K. Ehn and C. J. Mundy (Algal light absorption within a highly scattering bottom layer of sea ice and its implications for primary production, submitted to Geophysical Research Letters, 2011) show that a large difference is observed between a point versus a volume estimation of absorption due to the high-scattering properties of sea ice. This difference is further shown to greatly affect primary production estimates through its implementation in a photosynthesis-irradiance relationship. They suggest that the use of the two-stream radiative transfer model of Perovich [1990] could be used to accurately estimate algal light absorption within sea ice when the law of energy conservation is applied. Furthermore, our model does not consider the spectral quality of transmitted shortwave radiation. Since both snow and ice are more transparent to blue and green light, and ice algae in turn have higher absorptivity in these wavelengths [Maykut and Grenfell, 1975], our model likely underestimated algal absorption, even though it reasonably reproduced integrated under-ice PAR. To rectify this, a future model should incorporate a spectral model such as Perovich [1990].

[44] Comparing the underestimated biomass from Figure 5c to biomass calculated when light and nutrient limitation is switched off in the model shows growth that is too fast 
a)
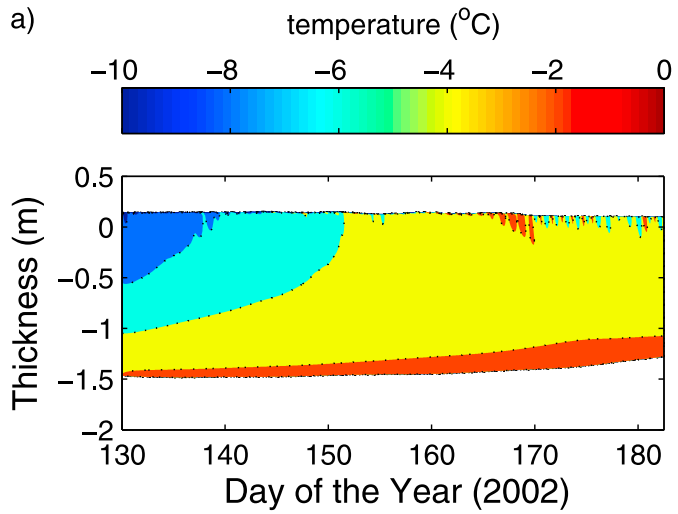

c)

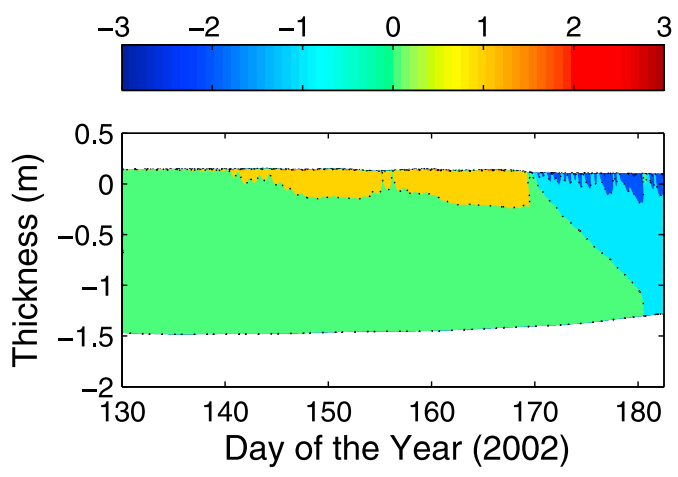

b)
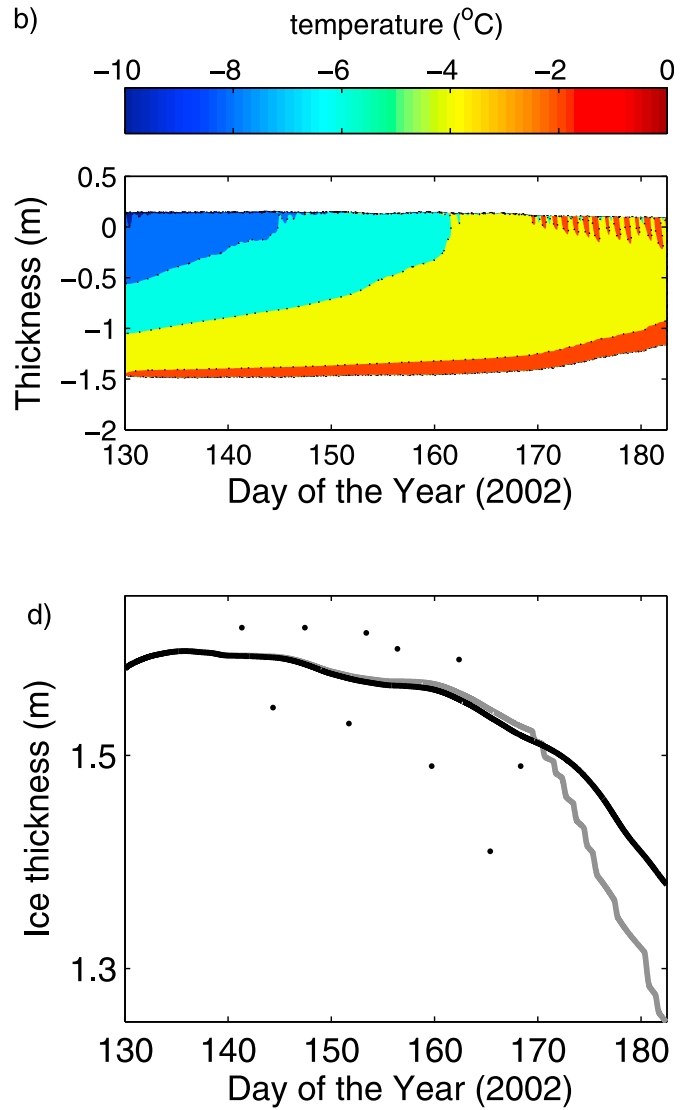

Figure 8. Simulated internal temperature and thickness evolution at the HSC site using (a) control run values for $i_{0}\left(0.5\right.$ for ice and 0.15 for snow) and (b) $i_{0}=0.18$ for ice and $i_{0}=0$ for snow. (c) The difference between Figures $8 \mathrm{a}$ and $8 \mathrm{~b}$ in the internal snow-ice temperature evolution and (d) the ice thickness observations (dots), total ice thickness for the control run (black line), and for the adjusted $i_{0}$ values (grey line).

(Figure 7). A further comparison to the case in which biomass is unrestricted by light conditions $\left(L_{\text {lim }}=1\right)$ shows a more reasonable match to observations (Figure 7). It seems that a light limitation at least as low as the nutrient limitation in this case (0.6-0.7) would effectively capture the growth seen in the first 10 days. This simulation of the biomass, with the growth in the first 10 days adjusted, will be used as the "control run" at the HSC site in sections 5.4.2-5.4.6.

\subsubsection{Surface Melting}

[45] All the simulated ice melting shown in Figure 3 can be attributed to basal melt. In this study the value for $i_{0}$ in the model is high enough to effectively capture the observed under-ice PAR. In doing so, shortwave radiation is absorbed more evenly through internal layers rather than focused at the surface, as it is with lower $i_{0}$ values. With less energy at the ice surface, less warming and melting of ice occur at the surface. Thus there seems to be a balance required between capturing sufficient under-ice PAR and accurately simulating surface melt. This raises interesting questions about how thermodynamic ice models calculate absorption of radiation. Adding to this slowed ice melt rate is the effect of brine pockets, which are parameterized in the model. Brine volume fractions in the ice nearly double over the simulation, moderating the temperature increase. Salinity at the ice surface is fixed to zero, and this value linearly increases deeper into the ice, with a maximum of about 4 psu at the ice base. This salinity profile follows the simulated salinity profile for June shown by Vancoppenolle et al. [2006], which reflects the salinity profile of first-year ice that has undergone some melting. Thus brine pockets have a larger effect on temperature in the internal layers than the surface. Figure $8 \mathrm{c}$ shows a comparison of the control run $\left(i_{0}=0.15\right.$ for snow and $i_{0}=0.5$ for ice) with a simulation that uses $i_{0}=0$ for snow and $i_{0}=0.18$ for ice. Before day 170 , the control run is warmer in the upper ice layers; this is because in this case more shortwave radiation penetrates the snow layers and allows some warming in the ice. In contrast, after snow disappears at day 171, there is less heating at the ice surface in this run. Regular spikes penetrating the upper ice/snow layers can be seen in Figures $8 \mathrm{a}, 8 \mathrm{~b}$, and $8 \mathrm{c}$ are due to the diurnal cycle. While these daily temperature oscillations show a general warming after day 170 in the simulation with reduced $i_{0}$ values (Figure $8 \mathrm{~b}$ ), it seems to cool at the surface in the control run (Figure $8 \mathrm{a}$ ). This may be because in the control run, energy for melting at the surface during the day is not large enough to compensate for the cooling at night. Overall the simulation with lower $i_{0}$ values melts ice more rapidly after day 170 , due to surface melt (Figure $8 \mathrm{~d}$ ). However, before day 170 ice melts slightly faster in the control run, likely because of the penetration of radiation through the snow. 

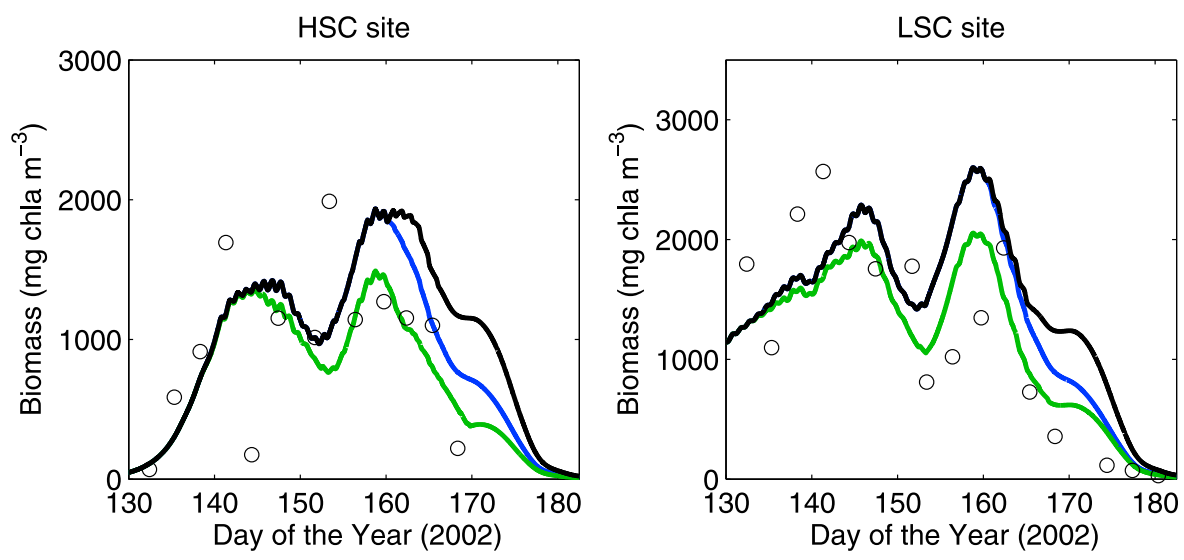

Figure 9. Observed (circles) and simulated biomasses at the (left) HSC and (right) LSC sites: the control run (black line) is compared to biomasses obtained using a melt lens parameterization (blue line) and using a melt lens parameterization combined with a flushing term (green line).

\subsubsection{Freshwater Lens}

[46] The simulated decline of the bloom occurs when algae lost from melt is larger than algal growth. The simulated rate at which the algae declines is slower than the observed decline (Figures 5d and 7). A likely explanation for the discrepancy is the presence of a freshwater layer produced under the ice, as with Michel et al. [1996]. Such a melt layer is not described by the model. This freshwater lens restricts nutrient exchange at the water-ice interface and consequently would slow ice algal growth. The first way by which it does this is through increased stratification below the ice, which reduces the upward mixing of nutrients. Second, the friction velocity becomes smaller, thereby increasing the viscous sublayer thickness and reducing diffusion of nutrients into the ice [Lavoie et al., 2005]. To accurately reproduce this effect, the relationship between the meltwater lens and friction velocity must be specified. If known, a parameterization can be added to the model, allowing snow and ice melt to influence the friction velocity. However, this process is poorly understood, and in the following we introduce a simple restriction to the model that halves the nutrient flux into the ice after the bloom begins its decline in early June. While this specific nutrient reduction cannot be justified, it gives an indication of how the melt lens could influence the end of the bloom. Including this condition does result in a more rapid bloom decline (see Figure 9). A more sophisticated handling of the meltwater lens that includes an increasingly limited nutrient flux may better describe the decline of the bloom.

\subsubsection{Brine Flushing}

[47] The effect of brine dynamics in the sea ice is not yet included in the model. Brine flushing, included in a brine dynamics model, is one process that becomes important during the spring melt. During this period, when the permeability threshold ( $5 \%$ brine volume) is reached, surface meltwater flows through the ice matrix [Vancoppenolle et al., 2007]. With meltwater moving through the brine channels, it is difficult for ice algae to maintain their position in the ice and algal loss from the ice increases [Krembs et al., 2001]. At both sites, snow is melting during the study period and flushing of nutrients and algae should be taken into account. It may be especially important at the HSC site, where the thicker snow cover and its larger source of meltwater could favor more flushing as the snow melts. To study the sensitivity of the biomass bloom to flushing, we add a simple loss term to the biomass equation. This term is arranged in the equation such that when the surface melt rate increases, the loss of biomass is correspondingly higher. This term is only active when the permeability threshold is reached. In field experiments, once the brine network is permeable, the flushing of meltwater through the ice is almost immediate [Vancoppenolle et al., 2007]. We thus compute the new algal loss using the simultaneous surface ice/snow melt at that time

$$
\frac{\partial B}{\partial t}=B\left[\mu-G+\phi \frac{\partial s_{i}}{\partial t}\right],
$$

where $\phi=0.03 \mathrm{~m}^{-1}$ is used as an estimate that gives a reasonable amount of biomass loss. After adding this new loss term, modeled biomass later in the bloom is significantly reduced and more in line with observations (Figure 9). Drops in the simulated biomass levels are now seen most notably between day 151 and 154, corresponding to a period with significant loss of snow. At both sites, simulated biomass fits more closely with observations in the second half of the study period, when brine dynamics are expected to increase algae lost due to melt.

[48] This new term is primitive, since, for example, the density effects of the ice/snow and water are not considered. The size of this loss term is also only an estimate, and may be either too large or too small. However, the results in Figure 9 show that having algal loss from flushing during the melt period does improve on the overall performance of the model. The purpose of this experiment was to show that results presented in section 5.3 can be improved upon by including brine dynamics in the model, and that this is necessary to accurately model ice algae. This experiment only dealt with brine flushing and melt lens, but brine gravity drainage would also contribute to algal losses due to melt. In the future, the brine dynamics model of Vancoppenolle et al. [2007] will be included, using ice algae and nutrients as dynamic tracers in the brine channels (see future work in section 6). 

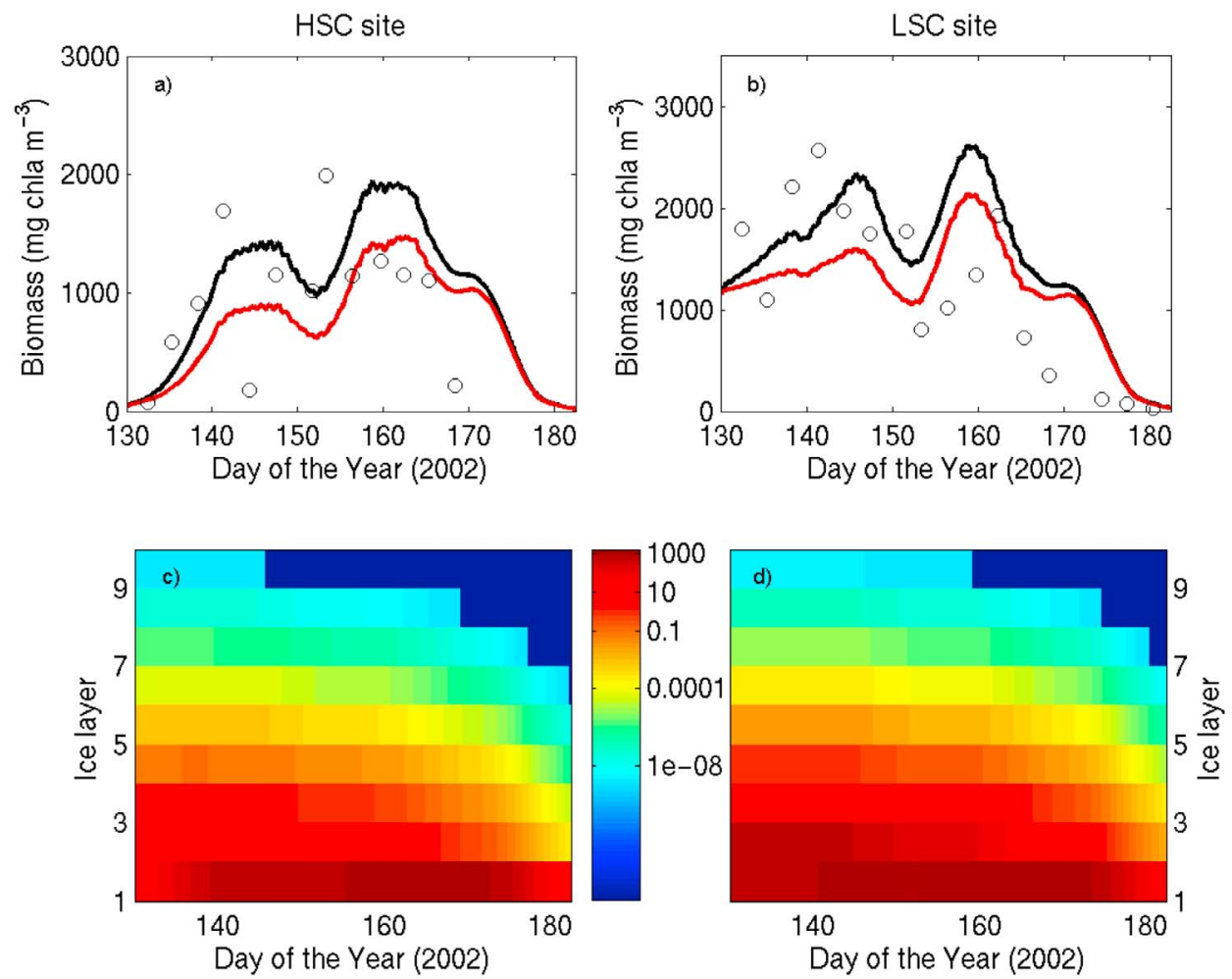

Figure 10. Observed (circles) and simulated biomasses for the (a) HSC and (b) LSC sites: the control run (black line) is compared to a simulation where algae are allowed to be transported into higher layers (red line). Time series of biomass in the bottom 10 ice layers (in $\mathrm{mg}$ chla $\mathrm{m}^{-3}$ ) for the (c) HSC and (d) LSC sites.

\subsubsection{Self Shading}

[49] This model allows for algal growth through all ice layers, something that was not possible in the Lavoie et al. [2005] model. With $w_{\max }$ defined as $1.7 \mathrm{~cm} \mathrm{~d}^{-1}$ [Krembs et al., 2001], the ice always grows slowly enough that algae can maintain their position in the bottom two ice layers. Although the ice base is where the overwhelming majority of ice algae are found in Arctic coastal ice blooms, it is possible that through the interconnection of brine channels, algae are able to grow upward into the ice [Horner et al., 1992]. Indeed, observations of chla concentrations in the Resolute area are more vertically extensive in later spring until the bloom decline [Cota et al., 1991]. While algae closer to the top of the ice would receive more light, nutrients may be less accessible. In addition, algae growing at the base of the ice will be partly shaded from algae higher in the ice. To investigate self shading of ice algae, we choose $w_{\max }=0.5 \mathrm{~cm} \mathrm{~d}^{-1}$, which lets a fraction of the algae grow into the ice. In addition, we more evenly divide the biomass in the two bottom ice layers, to examine self shading within the bottom algae community. At the HSC site, the 2 bottom ice layers initially have $25 \mathrm{mg}^{-3} \mathrm{~m} \mathrm{~m}^{-3}$ each, and at the LSC site, each have $600 \mathrm{mg}^{\text {chla m}}{ }^{-3}$, while all other layers have zero biomass. The results (see Figure 10a) show a significant decrease in the total biomass in the bottom two layers reached at both sites. The total amount of biomass transported above the bottom two layers is not significant (Figure 10b), with the decrease mostly owing to shading of the bottom layer by the layer above it. Thus, the effect of self shading is only significant if it is considered where algae is largely concentrated (ie, the ice base).

\subsubsection{Basal Melt Loss}

[50] The majority of the ice melt occurs at the ice base during the study period, when there is still an insulating snow cover. Since algal loss is dependent on the ice melt rate, the flux of heat from the ocean is an important controlling factor on the bloom. Here we look at the sensitivity of the algal bloom to 3 different treatments of the oceanic heat flux. In this study as well as that by Lavoie et al. [2005], tidal cycle data are used to calculate the oceanic heat flux. We compare this forcing (referred to here as ocean flux 1) to heat fluxes calculated with constant values of $u_{\tau}$ and $C_{o i}$, as with Huwald et al. [2005], providing upper and lower bounds to the control flux (see Figure 11). These comparison fluxes are called ocean flux 2 and ocean flux 3 , calculated with $C_{o i}=0.001$ and $u_{\tau}=0.065$ and $u_{\tau}=0.035$, respectively. A comparison of the three daily mean oceanic heat fluxes shows that the higher value of $u_{\tau}$ gives a larger heat flux into the ice (see Figure 11). Of the model results obtained using each of the fluxes, the ice thickness evolutions all fit reasonably with observations. As expected, the larger the oceanic heat flux into the ice, the more ice melt occurred. The effect of the different ice thickness evolutions on the algal bloom is presented in Tables $3 \mathrm{a}$ and $3 \mathrm{~b}$. It shows a direct impact on biomass by loss of ice at the ice base. Comparing ocean fluxes 1 and 3 shows a reduction in total basal ice melt over the study period by a factor of about 


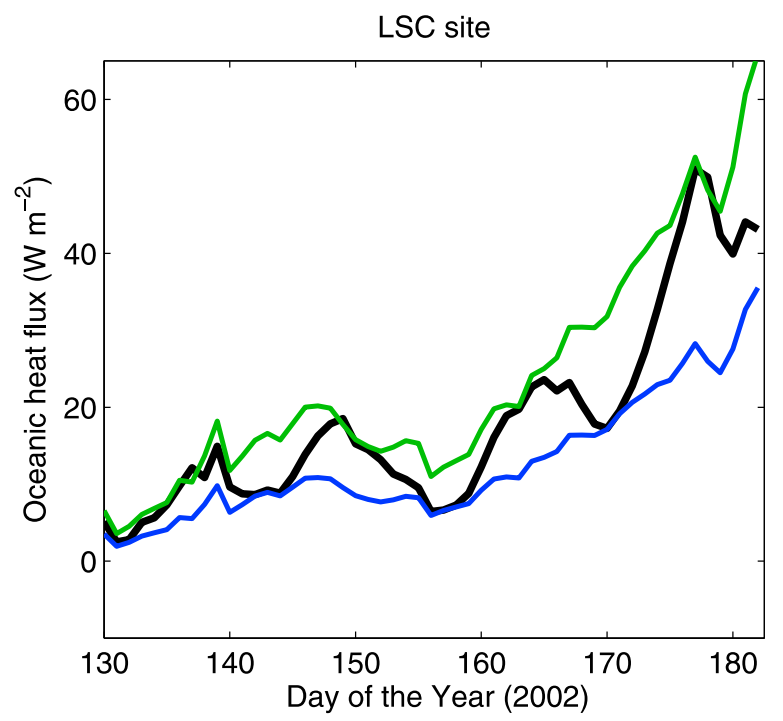

Figure 11. The oceanic heat flux used in the control run (black line), ocean flux 2 with $u_{\tau}$ set to $0.065 \mathrm{~m} \mathrm{~s}^{-1}$ (green line), and ocean flux 3 with $u_{\tau}$ set to 0.035 (blue line).

1.7 at both sites, with a corresponding increase in average biomass over the study period by a factor of about 1.9 .

[51] As described in section 4, the number of ice layers chosen was 90 , giving a mean ice thickness of $1.5 \mathrm{~cm}$. To examine what effect the ice layer thickness has on results, a similar ocean heat flux test was conducted with half as many ice layers, giving an ice layer thickness closer to $3 \mathrm{~cm}$. With thicker layers, ice algae in the bottom layer are less concentrated and therefore there is less algae lost from ice melt. Tables $3 \mathrm{a}$ and $3 \mathrm{~b}$ show that while total basal ice melt remains similar to the control run, much more ice algae accumulates. In addition, while in the comparison between ocean fluxes 1 and 3, average total biomass in the control run increases by a factor of about 1.9, it increases in the experimental run by only a factor of 1.5. The sensitivity of the algae at the ice base to the ocean flux is therefore dependent on ice layer thickness. The correct thickness of the basal algal community should ideally be independent of the number of ice layers chosen, and this will be subject to further study.

\section{Conclusion}

[52] We have introduced a new snow-ice algae-nutrient column model, developed by coupling the ice algae-nutrient model of Lavoie et al. [2005] with the thermodynamic $\sigma$

Table 3a. Basal Ice Melt and Biomass Relationship for $1.5 \mathrm{~cm}$ Ice Layer Thickness ${ }^{\mathrm{a}}$

\begin{tabular}{cccccc}
\hline & \multicolumn{2}{c}{ HSC Site } & & \multicolumn{2}{c}{ LSC Site } \\
\cline { 2 - 3 } \cline { 5 - 6 } Flux & $\begin{array}{c}\text { Accumulated Basal } \\
\text { Ice Melt }(\mathrm{cm})\end{array}$ & $\begin{array}{c}\text { Average Biomass } \\
\left(\mathrm{mg} \mathrm{chla} \mathrm{m}^{-3} \mathrm{~d}^{-1}\right)\end{array}$ & $\begin{array}{c}\text { Accumulated } \\
\text { Basal } \\
\text { Ice Melt }\end{array}$ & $\begin{array}{c}\text { Average } \\
\text { Biomass }\end{array}$ \\
\hline 1 & 21.92 & 995.6 & & 20.82 & 1500 \\
2 & 29.09 & 437.3 & & 27.95 & 974.5 \\
3 & 13.04 & 1897.9 & & 11.98 & 2818.2 \\
\hline
\end{tabular}

${ }^{\mathrm{a}}$ Described in section 5.4.6.
Table 3b. Basal Ice Melt and Biomass Relationship for $3.0 \mathrm{~cm}$ Ice Layer Thickness ${ }^{\mathrm{a}}$

\begin{tabular}{cccccc}
\hline & \multicolumn{2}{c}{ HSC Site } & & \multicolumn{2}{c}{ LSC Site } \\
\cline { 2 - 3 } \cline { 6 - 6 } Flux & $\begin{array}{c}\text { Total Basal } \\
\text { Ice Melt }(\mathrm{cm})\end{array}$ & $\begin{array}{c}\text { Average Biomass } \\
\left(\mathrm{mg} \mathrm{chla} \mathrm{m}^{-3} \mathrm{~d}^{-1}\right)\end{array}$ & & $\begin{array}{c}\text { Total Basal } \\
\text { Ice Melt }\end{array}$ & $\begin{array}{c}\text { Average } \\
\text { Biomass }\end{array}$ \\
\hline 1 & 22.27 & 1244.0 & & 21.05 & 2493.5 \\
2 & 29.47 & 877.8 & & 28.50 & 1825.5 \\
3 & 13.08 & 1804.9 & & 12.18 & 3544.0 \\
\hline
\end{tabular}

${ }^{\mathrm{a}}$ Described in section 5.4.6.

coordinate sea ice model of Huwald et al. [2005]. Model results were compared to observations made in Resolute Passage during spring-summer 2002.

[53] A new feature of our multilayer thermodynamic model is its capability to model algae in all layers within the ice, and to move algae between layers. This feature allows the physics itself to determine the vertical extent of nutrients and ice algae, offering an alternative to the bulk ice algae models presented in the past. Partitioning the algae at the ice base into separate layers can help to include the effect of self shading by the algae. In this particular study, results suggest that allowing a small amount of ice algae to grow into the interior of the ice does not have much of an effect on the growth of algae concentrated at the ice base.

[54] The ice algae were found to be light limited at the beginning of the bloom, transitioning to a nutrient limitation by the bloom end. However, there were difficulties in matching simulated and observed under-ice PAR. Attaining the correct combination of light attenuation and extinction coefficients $\left(\kappa_{s}, \kappa_{i}, i_{0}\right)$, while accurately modeling the ice thickness evolution, is not a straightforward task. Findings in both the literature and results presented here suggest that with changing snow and ice conditions over the melt season, $\kappa_{s}$ and $\kappa_{i}$ should decrease over time, reducing light attenuation with increased melting. As well, it is possible $i_{0}$ should increase as the melt season progresses, allowing more light to penetrate the surface layer. Especially in the case of $i_{0}$ for snow, the choices for these parameters are not well known. Similar differences between simulated and observed underice PAR are given by Lavoie et al. [2005]. In order to effectively simulate ice algae at the ice base, this area requires further study.

[55] Our results show that ice melt has a large impact on algal biomass content at the ice base. Ice melt rate determines the amount of algae lost to the water column [Michel et al., 2006], through a direct impact on the ice algae habitat as well as through flushing and its effect on nutrient availability. Because ice melt is so important to the fate of the algal bloom, we introduced primitive parameterizations of brine flushing and melt water at the ice base. A closer match to observations using these parameterizations suggests that these mechanisms enhance the decline of the bloom. Therefore in addition to ice melt rate, it seems ice structure is an important controlling factor of the algal bloom as well, in agreement with past studies [e.g., Gosselin et al., 1986; Krembs et al., 2001].

[56] Snow cover is also a dominant factor in controlling algal bloom dynamics. Through its influence on ice melt rate, a disappearing snow cover plays an important role in the bloom decline. In addition, a thicker snow cover provides more freshwater during melting, contributing to the 
flushing and melt water lens effects during the bloom decline. These findings support past ice algae studies pinpointing snow cover as a dominant factor controlling bloom dynamics [e.g., Mundy et al., 2005; Lavoie et al., 2005; Welch and Bergmann, 1989].

[57] Early in the bloom, the snow thickness is the harshest attenuator of light, thereby restricting algal growth. Model results, however, severely underestimate the algal growth rate under a deep snow cover $(10-20 \mathrm{~cm})$. This result raises serious issues of how to parameterize photosynthetic parameters in the algal growth rate, in order to accurately model ice algae under changing conditions. It also raises the issue of how radiative transfer and shortwave radiation is represented in one-dimensional ice models. To accurately parameterize the light reaching the algal community at the ice base, a snow thickness distribution may be required to take into account light from all directions. As well, shortwave radiation should be partitioned into different wavelenghts to account for the varying effects from the snow and ice, and on algal growth. Another issue raised by this study is that to effectively capture under-ice PAR, there is a trade-off with energy at the surface. Using a larger value of $i_{0}$ to allow the penetration of light, for example, translates into less energy at the surface to warm and melt the ice there. This is another aspect of the model that could be improved.

[58] Ice algae also seem to be strongly impacted by changing ocean conditions. Small changes to the oceanic heat flux, through its effect on basal ice melt, yield significant changes in biomass levels. The strong sensitivity to this parameterization is of concern, since the small-scale features such as the melt water lens and stratification are not properly resolved in current high-resolution ice-ocean models. It is also important to ensure the basal algal community thickness in the ice is properly resolved, since differing thicknesses have a large impact on algal loss at the ice base.

[59] Given the fragile balance of ideal nutrient, light and substrate conditions at the ice base, it is no surprise that the algae are so strongly influenced by ice melt, water column stratification and other physical conditions. While this paper introduced a snow-ice algae-nutrient model that is more physically sound than past model studies, it also revealed the need for improvements. Results suggest that being able to accurately simulate physical conditions at the ice base, especially brine dynamics, is essential before ice algae can be reliably modeled.

[60] After issues have been addressed, the next development of this model will handle the presence of algae in the ice interior more realistically. To this end, we will include two more sources of nutrients: through brine drainage from higher in the ice, and in situ regeneration of biogenic materials. Processes such as brine drainage will be represented in the model when it is coupled to the brine dynamics model of Vancoppenolle et al. [2007]. In addition to brine drainage, a more sophisticated parameterization of brine flushing will be added, enabling the model to capture the loss of algae during melt more effectively.

[61] Acknowledgments. Support for this work came from a PGS NSERC scholarship awarded to L. Pogson and two NSF Office of Polar Program grants (OPP-0230325 and OPP-0230264), an NSERC Discovery grant, and an Arctic Science Program grant (ARC-0520496) awarded to B. Tremblay. The field program was funded by a Science Strategic grant (Fisheries and Oceans Canada) to C. Michel. Special acknowledgements go to Rick Marsden for providing the meteorological data, the late Grant Ingram for under-ice temperature data, and C. J. Mundy and Jens Ehn for their input on the manuscript. We also thank B. LeBlanc, T. Juul-Pedersen, M. Kullman, and V. Rioux for help in the field and the Polar Continental Shelf Project for invaluable logistics support for the field program.

\section{References}

Arrigo, K. R., J. N. Kremer, and C. W. Sullivan (1993), A simulated Antarctic fast-ice ecosystem, J. Geophys. Res., 98(C4), 6929-6946.

Cota, G. F., and E. P. W. Horne (1989), Physical control of Arctic ice algal production, Mar. Ecol. Prog. Ser., 52, 111-121.

Cota, G. F., and R. E. H. Smith (1991), Ecology of bottom ice algae: Part II. Dynamics, distributions and productivity, J. Mar. Syst., 2, 279-295.

Cota, G. F., L. Legendre, M. Gosselin, and R. G. Ingram (1991), Ecology of bottom ice algae: Part I. Environmental controls and variability, J. Mar. Syst., 2, 257-277.

Eide, L., and S. Martin (1975), The formation of brine drainage features in young sea ice, J. Glaciol., 14, 137-154.

Eppley, R. W. (1972), Temperature and phytoplankton growth in the sea, Fish. Bull., 70, 1063-1085.

Flato, G. M., and R. D. Brown (1996), Variability and climate sensitivity of landfast Arctic sea ice, J. Geophys. Res., 101(C10), 26,767-26,777.

Golden, K. M., S. F. Ackley, and V. I. Lytle (1998), The percolation phase transition in sea ice, Science, 282, 2238-2241.

Gosselin, M., L. Legendre, J.-C. Therriault, S. Demers, and M. Rochet (1986), Physical control of the horizontal patchiness of sea-ice microalgae, Mar. Ecol. Prog. Ser., 29, 289-298.

Gradinger, R. (1999), Vertical fine structure of the biomass and composition of algal communities in Arctic pack ice, Mar. Biol., 133, 745-754.

Gradinger, R. (2009), Sea-ice algae: Major contributors to primary production and algal biomass in the Chukchi and Beaufort Seas during May/ June 2009, Deep Sea Res. Part II, 56, 1201-1212.

Gradinger, R., and Q. Zhang (1997), Vertical distribution of bacteria in sea ice from the Barents and Laptev seas, Polar Biol., 17, 448-454

Gradinger, R., M. R. Kaufman, and B. A. Bluhm (2009), Pivotal role of sea ice sediments in the seasonal development of near-shore Arctic fast ice biota, Mar. Ecol. Prog. Ser., 394, 49-63.

Grenfell, T. C., and G. A. Maykut (1977), The optical properties of ice and snow in the Arctic basin, J. Glaciol., 18, 445-463.

Horner, R. A., S. F. Ackley, G. S. Dieckmann, B. Gulliksen, T. Hoshiai, L. Legendre, I. A. Melnikov, W. S. Reeburgh, M. Spindler, and C. W. Sullivan (1992), Ecology of sea ice biota. Part 1. Habitat, terminology, and methodology, Polar Biol., 12, 417-427.

Huwald, H., L.-B. Tremblay, and H. Blatter (2005), A multilayer sigmacoordinate thermodynamic sea ice model: Validation against Surface Heat Budget of the Arctic Ocean (SHEBA)/Sea Ice Model Intercomparison Project Part 2 (SIMIP2) data, J. Geophys. Res., 110, C05010, doi:10.1029/2004JC002328

Jin, M., C. J. Deal, J. Wang, K. H. Shin, N. Tanaka, T. E. Whitledge, S. H. Lee, and R. R. Gradinger (2006), Controls of the landfast ice-ocean ecosystem offshore Barrow, Alaska, Ann. Glaciol., 44, 63-72.

Johannessen, O. M., et al. (2004), Arctic climate change: Observed and modelled temperature and sea-ice variability, Tellus Ser. A, 56, 328-341.

Jones, E. P., J. H. Swift, L. G. Anderson, M. Lipizer, G. Civitarese, K. K. Falkner, G. Kattner, and F. McLaughlin (2003), Tracing Pacific water in the North Atlantic Ocean, J. Geophys. Res., 108(C4), 3116, doi:10.1029 2001JC001141.

Juul-Pedersen, T., C. Michel, and M. Gosselin (2008), Influence of the Mackenzie River plume on the sinking export of particulate material on the shelf, J. Mar. Syst., 74, 810-824.

Kirk, J. T. O. (Ed.) (1983), Light and Photosynthesis in Aquatic Ecosystems, 401 pp., Cambridge Univ. Press, New York.

Krembs, C., T. Mock, and R. Gradinger (2001), A mesocosm study on physical-biological interactions in artificial Arctic sea ice, Polar Biol., $24,356-364$.

Lavoie, D., K. Denman, and C. Michel (2005), Modeling ice algal growth and decline in a seasonally ice-covered region of the Arctic (Resolute Passage, Canadian Archipelago), J. Geophys. Res., 110, C11009, doi:10.1029/2005JC002922.

Lavoie, D., K. Denman, and R. W. Macdonald (2010), Effects of future climate change on primary productivity and export fluxes in the Beaufort Sea, J. Geophys. Res., 115, C04018, doi:10.1029/2009JC005493.

Light, B., G. A. Maykut, and T. C. Grenfell (2003), Effects of temperature on the microstructure of first-year Arctic sea ice, J. Geophys. Res., 108 (C2), 3051, doi:10.1029/2001JC000887. 
Light, B., T. C. Grenfell, and D. K. Perovich (2008), Transmission and absorption of solar radiation by Arctic sea ice during the melt season, J. Geophys. Res., 113, C03023, doi:10.1029/2006JC003977.

Maykut, G. A. (1985), The ice environment, in Sea Ice Biota, edited by R. A. Horner, pp. 21-82, CRC Press, Boca Raton, Fla.

Maykut, G. A., and T. C. Grenfell (1975), The spectral distribution of light beneath first-year sea ice in the Arctic Ocean, Limnol. Oceanogr., 20, 554-563.

McPhee, M. G. (1992), Turbulent heat flux in the upper ocean under sea ice, J. Geophys.Res., 97(C4), 5365-5379.

Meiners, K., R. Gradinger, J. Fehling, G. Civitarese, and M. Spindler (2003), Vertical distribution of exopolymer particles in sea ice of the Fram Strait (Arctic) during autumn, Mar. Ecol. Prog. Ser., 248, 1-13.

Mellor, G. L., and L. H. Kantha (1989), An ice-ocean coupled model, J. Geophys. Res., 94(C4), 10,937-10,954.

Michel, C., L. Legendre, R. G. Ingram, M. Gosselin, and M. Levasseur (1996), Carbon budget of sea-ice algae in spring: Evidence of a significant transfer to zooplankton grazers, J. Geophys. Res., 101(C8), $18,345-18,360$.

Michel, C., R. G. Ingram, and L. R. Harris (2006), Variability in oceanographic and ecological processes in the Canadian Arctic Archipelago, Prog. Oceanogr., 71, 379-401.

Morel, A., and R. C. Smith (1974), Relation between total quanta energy for aquatic photosynthesis, Limnol. Oceanogr., 19, 591-600.

Mundy, C. J., D. G. Barber, and C. Michel (2005), Variability of snow and ice thermal, physical and optical properties pertinent to sea ice algae biomass during spring, J. Mar. Syst., 58, 107-120.

Mundy, C. J., J. K. Ehn, D. G. Barber, and C. Michel (2007), Influence of snow cover and algae on the spectral dependence of transmitted irradiance through Arctic landfast first-year sea ice, J. Geophys. Res., 112, C03007, doi:10.1029/2006JC003683.

Mundy, C. J., et al. (2009), Contribution of under-ice primary production to an ice-edge upwelling phytoplankton bloom in the Canadian Beaufort Sea, Geophys. Res. Lett., 36, L17601, doi:10.1029/2009GL038837.

Nishi, Y., and S. Tabeta (2007), Effects of atmospheric heat input on the release of organic carbon from sea ice, J. Mar. Syst., 67, 155-169.

Ohmura, A. (1984), Comparative energy balance study for Arctic tundra, sea surface glaciers and boreal forests, Geojournal, 8, 221-228.

Pabi, S., G. L. van Dijken, and K. R. Arrigo (2008), Primary production in the Arctic Ocean, 1998-2006, J. Geophys. Res., 113, C08005, doi:10.1029/2007JC004578

Parkinson, C. L., and W. M. Washington (1979), A large-scale numerical model of sea ice, J. Geophys. Res., 84(C1), 311-337.

Perovich, D. K. (1990), Theoretical estimates of light reflection and transmission by spatially complex and temporally varying sea ice covers, J. Geophys. Res., 95(C6), 9557-9567, doi:10.1029/JC095iC06p09557.

Renaud, P. E., A. Riedel, C. Michel, N. Morata, M. Gosselin, T. JuulPedersen, and A. Chiuchiolo (2007), Seasonal variation in benthic community oxygen demand: A response to an ice algal bloom in the Beaufort Sea, Canadian Arctic?, J. Mar. Syst., 67, 1-12.
Rozanska, M., M. Gosselin, M. Poulin, J. M. Wiktor, and C. Michel (2009), Influence of environmental factors on the development of bottom ice protist communities during the winter-spring transition, Mar. Ecol. Prog. Ser., 386, 43-59.

Sarthou, G., K. R. Timmermans, S. Blain, and P. Tréguer (2005), Growth physiology and fate of diatoms in the ocean: A review, J. Sea Res., 53, $25-42$.

Smith, R. E. H., J. Anning, P. Clement, and G. Cota (1988), Abundance and production of ice algae in Resolute Passage, Canadian Arctic, Mar. Ecol. Prog. Ser., 48, 251-263.

Tamelander, T., M. Reigstad, H. Hop, M. L. Carroll, and P. Wassmann (2008), Pelagic and sympagic contribution of organic matter to zooplankton and vertical export in the Barents Sea marginal ice zone, Deep Sea Res. Part II, 55, 2330-2339.

Tedesco, L., M. Vichi, J. Haapala, and T. Stipa (2010), A dynamic Biologically active layer for numerical studies of the sea ice ecosystem, Ocean Modell., 35, 89-104.

Tennekes, H., and J. L. Lumley (Eds.) (1972), A First Course in Turbulence, 300 pp., MIT Press, Cambridge, Mass.

Untersteiner, N. (1961), On the mass and heat budget of Arctic sea ice, Arch. Meteorol. Geophys. Bioklimatol. Ser. A, 12, 151-182.

Vancoppenolle, M., T. Fichefet, and C. M. Bitz (2006), Modeling the salinity profile of undeformed Arctic sea ice, Geophys. Res. Lett., 33, L21501, doi:10.1029/2006GL028342.

Vancoppenolle, M., C. M. Bitz, and T. Fichefet (2007), Summer landfast sea ice desalination at Point Barrow, Alaska: Modeling and observations, J. Geophys. Res., 112, C04022, doi:10.1029/2006JC003493.

Vancoppenolle, M., H. Goosse, A. de Montety, T. Fichefet, B. Tremblay, and J.-L. Tison (2010), Modeling brine and nutrient dynamics in Antarctic sea ice: The case of dissolved silica, J. Geophys. Res., 115, C02005, doi:10.1029/2009JC005369.

Welch, H. E., and M. A. Bergmann (1989), Seasonal development of ice algae and its prediction from environmental factors near Resolute, N.W.T., Canada, Can. J. Fish. Aquat. Sci., 46, 1793-1804.

Zeebe, R. E., H. Eicken, D. H. Robinson, D. Wolf-Gladrow, and G. S Dieckmann (1996), Modeling the heating and melting of sea ice through light absorption by microalgae, J. Geophys. Res., 101(C1), 1163-1181.

D. Lavoie, Maurice Lamontagne Institute, Fisheries and Oceans Canada Mont-Joli, 850 Rte. de la Mer, P.O. Box 1000, QC G5H 3Z4, Canada.

C. Michel, Arctic Research Division, Freshwater Institute, Fisheries and Oceans Canada, 501 University Cr., Winnipeg, MB R3T 2N6, Canada.

L. Pogson, Canadian Ice Service, Environment Canada, 373 Sussex Dr., Ottawa, ON K1A 0H3, Canada. (lynn.pogson@ed.gc.ca)

B. Tremblay, Department of Atmospheric and Oceanic Sciences, McGill University, Room 945, Burnside Hall, 805 Sherbrooke St. W., Montreal, QC H3A 2K6, Canada.

M. Vancoppenolle, Institut d'Astronomie et de Géophysique Georges Lemaître, Université Catholique de Louvain, Bâtiment Marc de Hemptinne, 2 Chemin du Cyclotron, B-1348 Louvain-la-Neuve, Belgium. 